\title{
Polyfuran conducting polymers: Synthesis, properties, and applications
}

\author{
M.J. González-Tejera ，E. Sánchez de la Blanca , I. Carrillo
}

Departamento Química Física I, Facultad Ciencias Químicas, Universidad Complutense de Madrid, Ciudad Universitaria, 28040 Madrid, Spain Departamento Química Industrial y Polímeros, E.U.I.T. Industrial, Universidad Politécnica de Madrid, Ronda de Valencia 3, 28012 Madrid, Spain

\begin{abstract}
In this review, polyfuran ( $\mathrm{PFu}$ ) synthesis methods and the nucleation mechanism; the electrochemical, structural, morphological, and magnetic properties of $\mathrm{PFu}$; thermal behavior; theoretical calculations on $\mathrm{PFu}$, as well as its applications reported to date, have been compiled. Not only PFu homopolymers have been reviewed, but also PFu co-polymers, PFu bipolymers, and PFu composites. The results are listed, discussed, and compared. It is hoped that this assembly of all the relevant data might enhance knowledge about this conducting polymer and lead to new research fields.
\end{abstract}

Keywords: Polyfuran; Conducting polymers; Physico-chemical properties

\section{Contents}

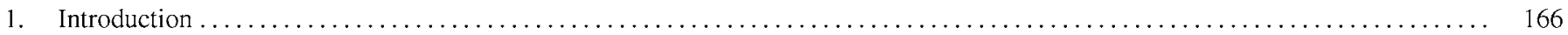

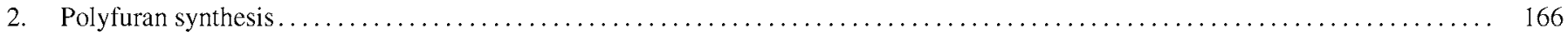

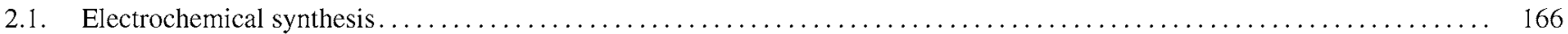

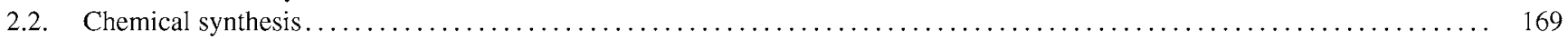

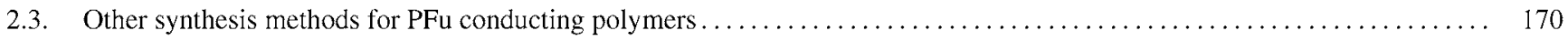

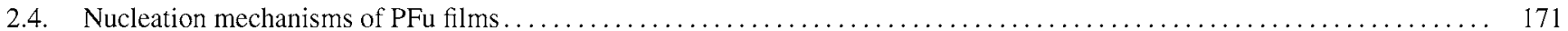

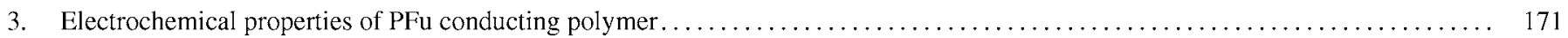

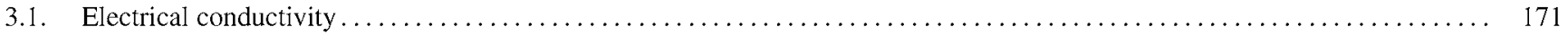

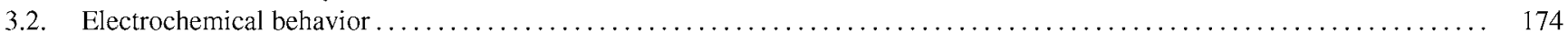

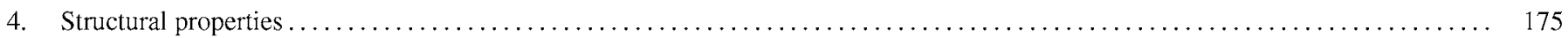

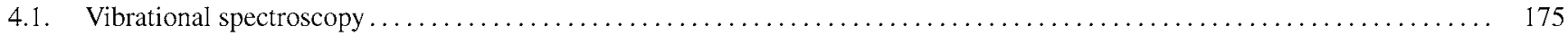

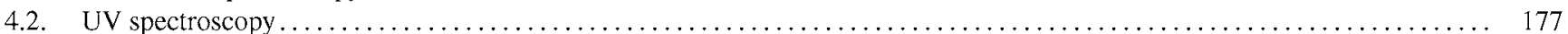

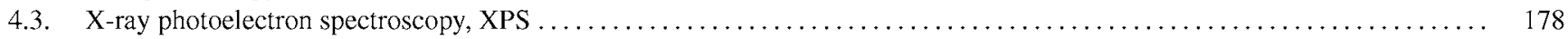

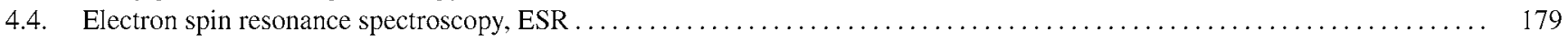

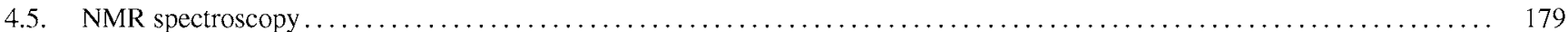

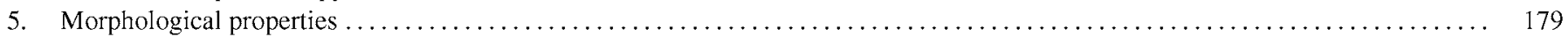

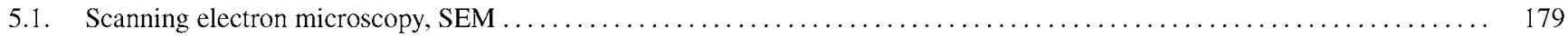

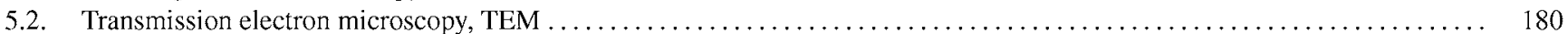

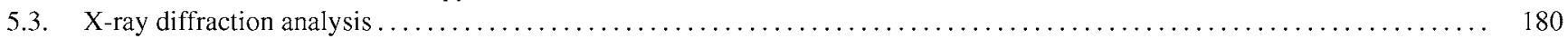

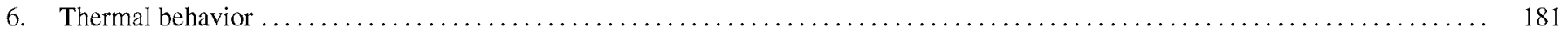

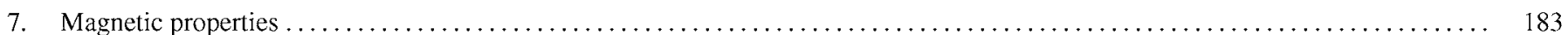

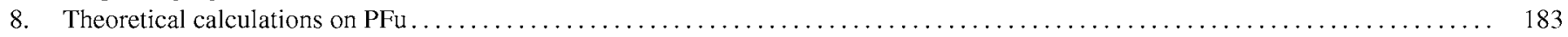

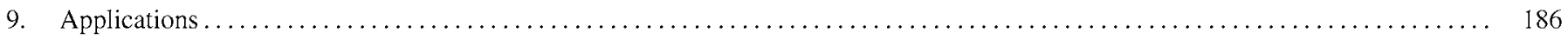




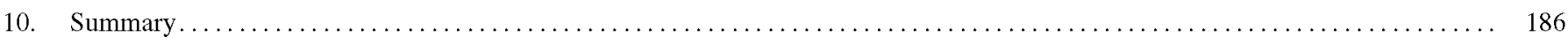

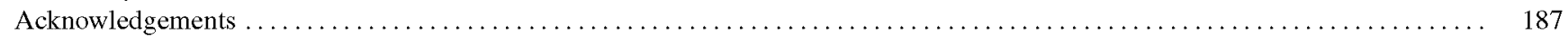

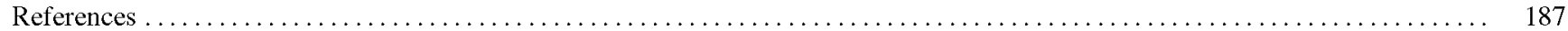

\section{Introduction}

Polymers based on heteroaromatic monomers have received considerable attention due to their interesting electrical, electrochemical, structural, mechanical, and optical properties. This review examines many of the recent advances in the conducting polymers field, in particular those related to polyfuran $(\mathrm{PFu})$.

Furan is one of the five-membered heteroaromatic ring compounds and has been extensively studied in terms of its reactivity, its specific physicochemical properties, and its technological applications in resin form PFu conducting polymers can be synthesized by both chemical and electrochemical methods in aqueous or organic media. Chemically, PFu has been synthesized by means of general routes applied in organic chemistry since 1964 and it has found many industrial applications as an insulating material.

Furan has attracted less attention than pyrrole, thiophene, aniline, etc., as a monomer in this context because of its high oxidation potential. Many authors have overcome this difficulty by changing the experimental conditions [9-33]. In addition, various composites [34-41], co-polymers [41-45], and bipolymers $[24,26]$ based on PFu have also been prepared.

Due to the possibility of combining the properties of polymers (processability, chemical stability, and magnetic properties) with those of metals (electrical conductivity, optical and magnetic properties) in a single material, each year the scope of the technological applications of conducting polymers is further extended. This may relate to the electronic excitations in their $\pi$-conjugated systems allowing the fabrication of electroluminescent diodes, applications in corrosion inhibition, or in microelectronics, etc. Therefore, it would seem desirable to have a panoramic view of the experimental methods for synthesizing $\mathrm{PFu}$, its electrochemical behavior in successive charge-discharge cycles, its electrical conductivity, etc.

The main focus of this review concerns studies on the electrochemical and chemical procedures hitherto used for synthesizing PFu. Moreover, nucleation, electrochemical behavior, and conductivity are included, with a description of the different experimental conditions in each case. The structures of PFu homopolymers, PFu composites, PFu co-polymers, and PFu bipolymers have been analyzed using different spectroscopic techniques, principally IR spectroscopy, and this topic is also covered herein. The morphologies of these films have been studied by scanning and transmission electron microscopies, their thermal behavior and magnetic properties have been analyzed, and theoretical calculations have been performed, and these issues are also addressed. Finally, an overview of the applications of PFu reported to date is presented.

\section{Polyfuran synthesis}

\subsection{Electrochemical synthesis}

Electrochemical methods (EM) have been applied for polymerizing several monomers, such as pyrrole, aniline, etc.

Electropolymerization processes can be carried out by cyclic voltammetry (CV), at a constant potential (potentiostatically), at a constant current density (galvanostatically), or by coulometry.

In most cases, a potentiostatic method has been used by applying a positive potential; see Table 1 . A negative potential has only been used to obtain PFu by the reduction of 2,5-dibromofuran $(\mathrm{DBFu})$ in the presence of $\mathrm{Ni}$ (bipy) ${ }_{3}{ }^{2+}$. The same authors applied a very high potential $(10 \mathrm{~V})$ to obtain $\mathrm{PFu}$ by oxidation of neat furan. In some cases, a high-density oligomeric region at the interface has been detected Two potential steps, the first from 0.0 to $1.7 \mathrm{~V}$ and the second from 2.10 to $2.80 \mathrm{~V}$, have also been applied to a $\mathrm{Pt}$ disc for the electropolymerization of furan . Cyclic voltammetry (CV) and chronopotentiometry are among the other electrochemical methods used. The former has been more frequently employed, varying the potential range depending on other experimental conditions.

A great variety of experimental conditions for the electrochemical polymerization of furan have been developed in the last decades; these are compiled in Table 1.

In the following, we consider successively the influences of the solvent, the electrolyte salt, and the electrode.

The choice of the solvent and the electrolyte are important factors to take into account because the polymerization reaction is sensitive to the nucleophilicity of the environment in the region close to the electrode surface.

Aprotic solvents, which are poor nucleophiles, have been extensively used, such as acetonitrile (MeCN) , benzonitrile boron trifluoride diethyl etherate + diethyl ether (BFEE/DEE) dichloromethane $\left(\mathrm{CH}_{2} \mathrm{Cl}_{2}\right)$ and acetonitrile/boron trifluoride/diethyl ether $\left(\mathrm{MeCN} / \mathrm{BF}_{3} / \mathrm{DEE}\right)$ mixture In some cases, the presence of a small quantity of water proved to be necessary to obtain the polymer Wan

analyzed the effect of the water content in the medium. They found that the electrochemical activity of $\mathrm{PFu}$ was partly lost in dry MeCN solutions and was totally lost in aqueous solutions, as confirmed by spectroscopic studies. However, in the case of polypyrrole production by electropolymerization, the addition of a small amount of water was found to have a great influence on the properties of the polymer due to stabilization of the radical cation intermediate by the polar water molecules Nevertheless, an anhydrous electrolytic medium was noted by del Valle and González-Tejera et al. as the best conditions for obtaining an adherent polymer. 
Table 1

Different experimental conditions for electropolymerization Polyfuran conducting films

\begin{tabular}{|c|c|c|c|c|c|c|}
\hline Substrate & Electrolyte & Solvent & $\mathrm{EM}^{\mathrm{a}}$ & $t_{\mathrm{p}}(\mathrm{s})$ & [Monomer] (M) & $\begin{array}{l}\text { [Electrolyte] } \\
\text { (M) }\end{array}$ \\
\hline $\mathrm{Pt}$ & $\mathrm{Bu}_{4} \mathrm{NBF}_{4} \mathrm{~b}$ & $\begin{array}{l}\mathrm{MeCN}^{\mathrm{c}}+\mathrm{H}_{2} \mathrm{O} \\
\left(10^{-2} \mathrm{M}\right)\end{array}$ & $1.85 \mathrm{~V}(\mathrm{SCE})$ & - & $\mathrm{Fu}, 10^{-2}$ & - \\
\hline $\begin{array}{l}\text { Conducting } \\
\text { glass }\end{array}$ & $\mathrm{AgClO}_{4}$ & Benzonitrile & $1.8-2.5 \mathrm{~V}$ & - & $\mathrm{Fu}, 0.2-0.3$ & $0.1-0.2$ \\
\hline \multirow{4}{*}{$\begin{array}{l}\mathrm{Pt}, \mathrm{Au}, \mathrm{SnO}_{2} \\
\mathrm{Ag}, \mathrm{PbO}_{2} \\
\mathrm{RuO}_{2}\end{array}$} & $\mathrm{Bu}_{4} \mathrm{NClO}_{4}{ }^{\mathrm{d}}$ & $\mathrm{MeCN}$ & $1.8 \mathrm{~V}(\mathrm{SCE})$ & - & $\mathrm{Fu}, 5.10^{-2}$ & 0.5 \\
\hline & $\mathrm{LiClO}_{4}$ & & & & & \\
\hline & $" n$ & $" 1$ & $n$ & & $" 1$ & $" 1$ \\
\hline & & "1 & $" 1$ & & $" 1$ & $" 1$ \\
\hline $\mathrm{Pt}$ & $\mathrm{Bu}_{4} \mathrm{NBF}_{4}$ & $\mathrm{MeCN}$ & - & - & $\mathrm{Fu}, 10^{-2}$ & - \\
\hline (a) $\mathrm{Pt}$ & $\mathrm{Ni}(\text { bipy })_{3}{ }^{2+}$ & $\mathrm{MeCN}$ & $-2.0 \mathrm{~V}$ & - & $\begin{array}{l}\mathrm{DBFu}^{\mathrm{e}}, 10^{-2} \\
\text { Neat } \mathrm{Fu}\end{array}$ & $2 \times 10^{-2}$ \\
\hline (b) $\mathrm{Pt}$ & $\mathrm{Bu}_{4} \mathrm{NClO}_{4}$ & $\mathrm{MeCN}$ & $10 \mathrm{~V}$ & & $\mathrm{Fu}, 0.2$ & 0.5 \\
\hline (c) $\mathrm{Pt}$ & $\mathrm{Bu}_{4} \mathrm{NClO}_{4}$ & $\mathrm{MeCN}$ & $2.5 \mathrm{~V}\left(\mathrm{Ag} / \mathrm{Ag}^{+}\right)$ & & & 0.1 \\
\hline $\mathrm{Pt}$ & $\mathrm{Bu}_{4} \mathrm{NClO}_{4}$ & $\mathrm{MeCN}$ & $\mathrm{CV}^{\mathrm{f}}$ & - & $\begin{array}{l}\text { Fu: } 10^{-2} \\
2-\mathrm{MFu}^{\mathrm{g}}, 10^{-2} \\
\mathrm{DMFu}^{\mathrm{h}}, 10^{-2}\end{array}$ & 0.1 \\
\hline Stainless steel & $\mathrm{Et}_{4} \mathrm{NClO}_{4}{ }^{\mathrm{i}}$ & $\mathrm{MeCN}$ & $2 \mathrm{~V}(\mathrm{SCE})$ & - & $\mathrm{Fu}, 0.3 \mathrm{M}$ & 0.1 \\
\hline \multirow[t]{3}{*}{$\mathrm{Pt}$} & $\begin{array}{l}\mathrm{Bu}_{4} \mathrm{NCF}_{3} \mathrm{SO}_{3}{ }^{j} \\
\mathrm{Bu}_{4} \mathrm{NClO}_{4} \\
\mathrm{Bu}_{4} \mathrm{NBF}_{4} \\
\mathrm{Bu}_{4} \mathrm{NPF}_{6} \mathrm{k}\end{array}$ & MeCN & $\begin{array}{l}\mathrm{CV} \\
" 1\end{array}$ & - & $\begin{array}{l}\text { Terfuran, } \\
0.02\end{array}$ & $\begin{array}{l}0.05 \\
11\end{array}$ \\
\hline & & "1 & 11 & & "I & $" 1$ \\
\hline & & "1 & 11 & & 11 & $" 1$ \\
\hline $\mathrm{Pt}$ & $\mathrm{NaClO}_{4}$ & $\mathrm{MeCN}$ & $1.7,1.9$ & $\leq 340$ & $\mathrm{Fu}, 0.2-0.4$ & 0.2 \\
\hline 11 & $" 1$ & $" 1$ & $2.1,2.3 \mathrm{~V}(\mathrm{SCE})$ & $\leq 20$ & 11 & $" 1$ \\
\hline$" 1$ & $n$ & "1 & & 200 & $" 1$ & $" 1$ \\
\hline$" 1$ & $n$ & "1 & & $1-1600$ & $" 1$ & $" 1$ \\
\hline $\mathrm{Pt}$ & $\begin{array}{l}\mathrm{Bu}_{4} \mathrm{NBF}_{4} \\
\mathrm{Bu}_{4} \mathrm{NPF}_{6} \\
\mathrm{Bu}_{4} \mathrm{NclO}_{4}\end{array}$ & $\mathrm{MeCN}$ & $\begin{array}{l}1.5 \mathrm{~V}\left(\mathrm{Ag} / \mathrm{Ag}^{+}\right) \\
1.25 \mathrm{~V}\left({ }^{\prime \prime}\right)\end{array}$ & - & $\begin{array}{l}\mathrm{Fu}, 2.5 \cdot 10^{-3} \\
2-\mathrm{MFu}\end{array}$ & - \\
\hline Stainless or Pt & $\mathrm{Bu}_{4} \mathrm{NBF}_{4}{ }^{1}$ & BFEE/DEE ${ }^{m}$ & $\begin{array}{l}1.2 \mathrm{~V}(\mathrm{Ag} / \mathrm{AgCl}) \\
(0.1 \mathrm{M} \mathrm{KCl})\end{array}$ & 60,300 & $\begin{array}{l}0.1 \\
" 1 \\
" 1\end{array}$ & $\begin{array}{l}0.05 \\
" 1 \\
1 "\end{array}$ \\
\hline $\mathrm{Pt}$ & $\mathrm{Bu}_{4} \mathrm{NBF}_{4}$ & BFEE/DEE & $1 \mathrm{~mA} \mathrm{~cm}^{-2}$ & 600 & 0.1 & 0.05 \\
\hline $\mathrm{Pt}$ & $\mathrm{LiClO}_{4}$ & $\mathrm{MeCN}$ & $\mathrm{CV}$ & - & 0.1 & 0.2 \\
\hline $\begin{array}{l}\mathrm{Pt} \\
\|\end{array}$ & $\begin{array}{l}\mathrm{Et}_{4} \mathrm{NBF}_{4}{ }^{\mathrm{n}} \\
\mathrm{Bu}_{4} \mathrm{NPF}_{6}\end{array}$ & $\mathrm{MeCN}$ & $\begin{array}{l}2.44 \mathrm{~V}\left(\mathrm{Ag} / \mathrm{Ag}^{+}\right) \\
2.40 \mathrm{~V}\left({ }^{\prime \prime}\right)\end{array}$ & - & $\mathrm{Fu}, 0.1$ & $\begin{array}{l}0.2 \\
0.2\end{array}$ \\
\hline $\mathrm{Pt}, \mathrm{Au}$ & $\mathrm{LiClO}_{4}$ & $\begin{array}{l}\mathrm{BFEE} / \mathrm{DEE}+\mathrm{BF}_{3}(48.24 \\
\text { vol\%)+ } \mathrm{H}_{2} \mathrm{O}(0.25 \\
\text { vol } \%)\end{array}$ & $0.9 \mathrm{~V}\left(\mathrm{Ag} / \mathrm{Ag}^{+}\right)$ & - & $\mathrm{Fu}, 0.1$ & - \\
\hline $\operatorname{TiO}_{x}$ & $\mathrm{Bu}_{4} \mathrm{NClO}_{4}$ & $\mathrm{Cl}_{2} \mathrm{CH}_{2}{ }^{\circ}$ & $15 \mathrm{~V}$ & - & $\mathrm{Fu}, 0.1$ & 0.1 \\
\hline $\mathrm{Pt}$ & $\begin{array}{l}\mathrm{Et}_{4} \mathrm{NClO}_{4} \\
\mathrm{Bu}_{4} \mathrm{NPF}_{6} \\
\mathrm{Bu}_{4} \mathrm{NBF}_{4}\end{array}$ & $\begin{array}{l}\text { MeCN } \\
" \\
"\end{array}$ & $2.1-2.9 \mathrm{~V}(\mathrm{SCE})$ & 3600 & $\mathrm{Fu}, 0.1-0.05$ & $\begin{array}{l}0.1 \\
" 1 \\
" \prime\end{array}$ \\
\hline $\mathrm{Pt}$ & $\mathrm{Bu}_{4} \mathrm{NPF}_{6}$ & MeCN & $\begin{array}{l}\text { Two steps } \\
\text { potential: (a) } \\
0.0-1.7 \mathrm{~V} ; \text { (b) } \\
2.1-2.8 \mathrm{~V}\end{array}$ & $2-5$ & $0.05-0.5$ & $0.05-0.1$ \\
\hline $\mathrm{Pt}$ & $\mathrm{Bu}_{4} \mathrm{NBF}_{4}$ & $\begin{array}{l}\mathrm{MeCN} / \mathrm{BF}_{3} / \mathrm{DEE}(2 / 4 / 4 \\
\mathrm{v} / \mathrm{v} / \mathrm{v})[\mathrm{p}] \\
\mathrm{MeCN}\end{array}$ & $\begin{array}{l}1.4 \mathrm{~V}(\mathrm{Ag} / \mathrm{AgCl}) \\
2.0 \mathrm{~V}(\mathrm{Ag} / \mathrm{AgCl})\end{array}$ & 600 & $\mathrm{Fu}, 0.05 \mathrm{M}$ & - \\
\hline ITO & " & & & - & 11 & $0.05 \mathrm{M}$ \\
\hline
\end{tabular}


Table 1 (Continued)

\begin{tabular}{|c|c|c|c|c|c|c|}
\hline Substrate & Electrolyte & Solvent & $\mathrm{EM}^{\mathrm{a}}$ & $t_{\mathrm{p}}(\mathrm{s})$ & [Monomer] (M) & $\begin{array}{l}\text { [Electrolyte] } \\
\text { (M) }\end{array}$ \\
\hline $\mathrm{Pt}$ & $\mathrm{Bu}_{4} \mathrm{NBF}_{4}$ & BFEE/DEE & $\begin{array}{l}1.6-1.1 \mathrm{~V} \\
(\mathrm{Ag} / \mathrm{AgCl}) \\
(0.1 \mathrm{M} \mathrm{KCl})\end{array}$ & - & $\mathrm{Fu}, 0.1 \mathrm{M}$ & - \\
\hline
\end{tabular}

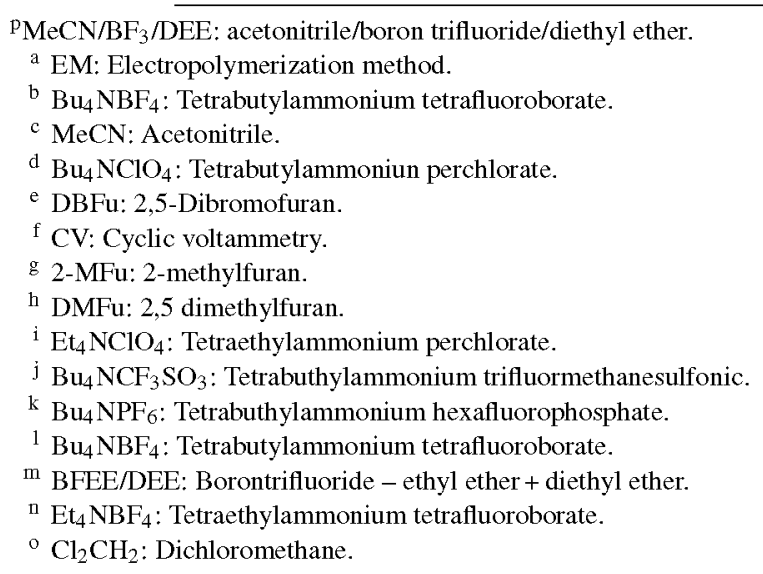

As regards the electrolyte salt, the main properties to consider are its solubility, its degree of dissociation, and its nucleophilicity. Tetraalkylammonium salts fulfil all of these criteria and are commonly used or sodium and silver perchlorates. The monomer and electrolyte concentrations strongly influence the quality of the resultant films. The higher the concentration of the monomer, the greater the electroactivity of the film The effect of the electrolyte concentration at a constant electropolymerization potential $\left(E_{\mathrm{p}}\right)$ and time $\left(t_{\mathrm{p}}\right)$ reveals that the furan concentration must be equal to or greater than that of the electrolyte $\left(\mathrm{NaClO}_{4}\right)$, since a higher electrolyte concentration has an inhibitory effect on the polymerization process

The size of the counteranion influences the microstructure, the porosity, and the conductivity of the polymer. It has been observed that the larger the counteranion, the higher the polymer conductivity

Most authors have used furan as the monomer for polyfuran synthesis, exceptions being Zotti et al. Nessakh et al.

$$
\text { and Glenis polyfuran (denoted as }
$$

$\mathrm{PF}$ ) was obtained by reduction of 2,5-dibromofuran (DBFu).

terfuran was employed as the monomer because of its considerably lower oxidation potential $(\sim 1.5 \mathrm{~V})$ compared to that of furan itself. No defined deposits were obtained from furan, 2-methylfuran (2-MFu), and 2,5-dimethylfuran (DMFu) in acetonitrile containing $\mathrm{Bu}_{4} \mathrm{NClO}_{4}$ by cyclic voltammetry on a platinum electrode

The nature of the working electrode is of great importance because the oxidative polymerization process must be separated from the oxidation potential of the metal. For this reason, platinum and gold have been the most frequently used, but a variety of other materials and compounds, such as tin oxide, silver, ruthenium oxide, and lead oxide , stainless steel titanium oxide , ITO and conducting glass have also been employed in the electrochemical production of PFu; see Table 1.
Generally, polyfuran synthesis has been carried out at room temperature, but Demirboğa and Önal found that the rate of furan polymerization increased with increasing temperature.

The influence of $t_{\mathrm{p}}$ on the synthesis has also been studied by analyzing the current response to a controlled potential perturbation at different applied times from 1 to $6000 \mathrm{~s}$ In the early stages of the electropolymerization process, the generation of active nuclei was favored; however, as $t_{\mathrm{p}}$ was increased, the rate of formation of the polymer films remained almost constant and the $\mathrm{PFu} / \mathrm{ClO}_{4}$ films became more compact.

As regards their color, $\mathrm{PFu}$ films vary from yellow (undoped state) to green dark blue and finally black (doped state) depending on the dopant anion and on $E_{\mathrm{p}}$.

PFu synthesis has been successfully accomplished by all of the above electrochemical methods, but the film quality and color were dependent on the aforementioned array of experimental parameters.

Some authors have tried to use PFu to prevent electrochemical corrosion of mild steel. They tried several aqueous $\left(\mathrm{H}_{2} \mathrm{O} / \mathrm{CH}_{3} \mathrm{OH}\right.$ or $\mathrm{H}_{2} \mathrm{O} / \mathrm{C}_{2} \mathrm{H}_{5} \mathrm{OH}$ at $33 \mathrm{vol} \%$ alcohol containing $0.005 \mathrm{M} \mathrm{H}_{2} \mathrm{SO}_{4}$ ) and organic (dimethylformamide or acetonitrile) media. Corrosion of the substrate and oxidation of the solvent were the main reactions observed due to the high oxidation potential of furan.

The final step in the abovementioned synthetic methods was the electrogeneration of polyfuran homopolymer films, but no information about the polymerization mechanism was given.

Different mechanisms for the electropolymerization of pyrrole have been proposed, but Diaz's mechanism is believed to be the correct one and we consider that it is also applicable to PFu (see Scheme 1). It begins with an electron-transfer step (a) to form a radical cation with several resonance forms, which is followed by consecutive chemical and electron-transfer reactions (b-d). Among them, a stabilization step involves the loss of two protons (c) and the generation of an aromatic dimer with a 
(a)

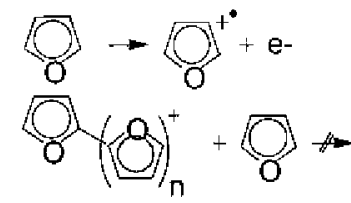

(c)

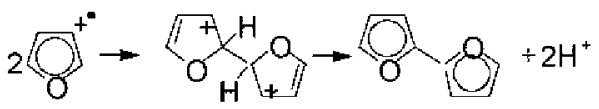

(d)

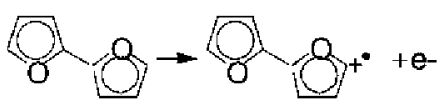

(e)

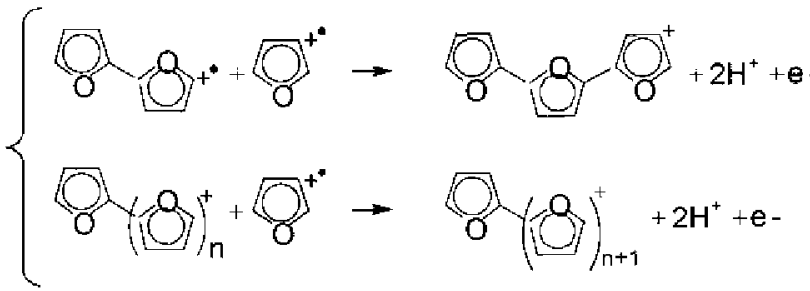

(f)

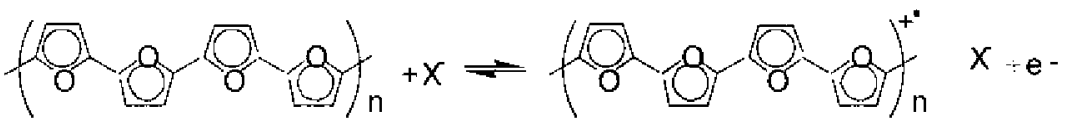

(g)

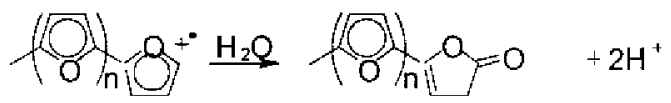

Scheme 1. Mechanism of PFu electrochemical polymerization.

bond between their $\alpha$-positions. The process continues with oxidation of the dimer forming different resonance forms (d). The most reactive of these reacts with a monomer radical to form a trimer dication because the oxidation potential of the dimer is lower than that of the monomer (e), which may then be deprotonated to give a neutral trimer. The reaction could be followed by a further electro-oxidation with coupling at the $\alpha, \alpha^{\prime}$-positions, thereby leading to a progressive increase in the chain length through the same sequence until the final polymer structure is obtained . Oxidation and a simultaneous doping process take place during the polymer generation, the oxidation potential of the monomer being lower than that of the polymerized species (f). Although the final step in the electropolymerization is not clear, Diaz believes that the presence of water could serve to complete the polymerization process $(\mathrm{g})$.

In order to enhance the properties of $\mathrm{PFu}$, bipolymers of polyfuran with other polymers have also been fabricated, such as polyfuran/polythiophene (PFu/PT) and polythiophene/polyfuran (PT/PFu); these were produced in MeCN with $\mathrm{LiClO}_{4}$ as the supporting electrolyte. In another work , the authors deduced that both the formation potentials of the bipolymers and their structures changed in dependence on the supporting electrolyte employed.

Electrochemical co-polymerization is an important method for modulating the properties of individual polymers. Some authors _ _ have successfully co-polymerized pyrrole and furan in a binary solvent (BFEE/DEE). The co-polymerization was performed under potentiostatic conditions $(1.2 \mathrm{~V})$ with an extremely low concentration of pyrrole $\left(4 \times 10^{-3} \mathrm{M}\right)$ com- pared with that of furan $(0.2 \mathrm{M})$. The same electrolyte, organic medium, and electrochemical method have been used to copolymerize furan $(0.05 \mathrm{M})$ and 3-methylthiophene $(0.1 \mathrm{M})$, which generated chains with alternating units

From the above considerations, it can be seen that different electrochemical procedures are available for the fabrication of PFu films, but it seems that the best method is to apply a constant potential, with a furan concentration generally higher than that of the electrolyte, and a non-aqueous solvent such as acetonitrile. This aprotic medium has low nucleophilicity, which is needed because the polymerization reaction proceeds via radical cation intermediates. There is some controversy about the need for the presence of a small amount of water in the aprotic medium.

\subsection{Chemical synthesis}

The chemical methods for polymerizing $\mathrm{Fu}$ monomer are described below, taking into account the fact that electrochemical routes generally have more advantages

Many publications have described the polymerization of $\mathrm{Fu}$ by acidic catalysts $\quad \mathrm{PFu}$ has also been chemically copolymerized with electron-deficient monomers, such as maleic anhydride, in a radical polymerization To the best of our knowledge, Armour et al. were the first to publish specific electrical conductance data for chemically synthesized $\mathrm{PFu}$. The catalyst used was trichloroacetic acid $\left(\mathrm{Cl}_{3} \mathrm{CCOOH}\right)$, application of which for $170 \mathrm{~h}$ at $20^{\circ} \mathrm{C}$ resulted in a polymer yield of $20 \%$. This catalyst was also employed by Lamb with the objective of determining the structures of the oligomers and 
polymers generated from furan. It was observed that when this acid was used, the polymer obtained was completely soluble in chloroform and dichloromethane.

Oxidative cationic polymerization of furan with Lewis acid catalysts under mild conditions is another chemical method that has been used to obtain PFu; catalysts used have included $\mathrm{FeCl}_{3}$ and $\mathrm{MoCl}_{5}$, which were deployed in anhydrous chloroform , dioxane, or $\mathrm{CH}_{3} \mathrm{NO}_{2}$, neat or in combination with $\mathrm{CH}_{2} \mathrm{Cl}_{2}$.

An intercalation method has also been applied to obtain $\mathrm{PFu}$

Furan, terfuran, and tetrafuran were the monomers used for intercalation in iron oxychloride (FeOCl), $\mathrm{PFu} / \mathrm{FeOCl}$. In the cases of furan and tetrafuran, the intercalation process was not completely achieved, whereas terfuran slowly reacted with FeOCl.

These oxidative methods generated great amounts of aliphatic products; therefore, McConnell attempted the polymerization with the mild oxidizing agent pyridinium chlorochromate (PCC), which provided the least amount of ring opening. Some years later, this group used the same oxidative method to obtain $\mathrm{PFu}$ and co-polymers of $\mathrm{Fu}$ with $2 \%$ pyrrole ( $\mathrm{PFu}-\mathrm{Py})$ or thiophene $(\mathrm{PFu}-\mathrm{Th})$ with the aim of increasing polymer stability . They avoided the ring opening by using anhydrous conditions for the polymerization process. The same group extended their study by synthesizing $\mathrm{PFu}$ and 10 co-polymers based on PFu with 1, 2, 3, 4, and 5\% of pyrrole or thiophene [45]. The chemical polymerization was again achieved by oxidative coupling with PCC as the oxidizing agent under anhydrous conditions.

Blends and composite materials have also been synthesized by chemical methods with a view to obtaining attractive mechanical and electrical properties suitable for technological applications. Composite materials, such as poly(o-toluidine) (POT) and $\mathrm{PFu}$, and $\mathrm{PFu}$ and polyaniline halogen derivatives such as poly(2-iodoaniline) (P2IAn), poly(2chloroaniline) (P2ClAn) , poly(2-fluoroaniline) (P2FAn) and poly(2-bromoaniline) (P2BrAn) , have been prepared. These composites were also prepared by changing the synthesis order of the host and guest polymers with the aim of improving the PFu processability, since PFu itself is both insoluble and infusible.

A new chemical synthesis method for preparing $\mathrm{PFu}$ was developed in order to study its electrorheological properties (ER). A dark-brown powder of $\mathrm{PFu}$ was obtained from the reaction of furan monomer and iodine dissolved in acetonitrile (Poly-1a) and a yellow-brown powder of PFu was obtained from the reaction of $\mathrm{Fu}$ monomer with neat iodine (Poly-1b)

A great challenge in the field of conducting polymers is their processability. To investigate this technological problem, Ballav and Biswas applied the widely accepted procedure for synthesizing polymer-inorganic oxide nanocomposite systems. They obtained PFu homopolymers and nanocomposites of $\mathrm{PFu}$ with $\mathrm{Al}_{2} \mathrm{O}_{3}$ and montmorillonite clay (MMT). PFu-MMT composite was directly obtained by injection of a known quantity of Fu into a weighed quantity of MMT without any extraneous oxidant. $\mathrm{PFu}-\mathrm{Al}_{2} \mathrm{O}_{3}$ nanocomposites were prepared using $\mathrm{FeCl}_{3}$
Table 2

Elemental analysis of different sample of doped polyfuran

\begin{tabular}{llll}
\hline Sample & $\% \mathrm{C}$ & $\% \mathrm{H}$ & $\% \mathrm{X}$ \\
\hline $\mathrm{PFu}^{-\mathrm{Bu}_{4} \mathrm{NClO}_{4}}$ & $74 \pm 1(\mathrm{C}+\mathrm{H}+\mathrm{O})$ & & $\mathrm{B}+\mathrm{F}=26 \pm 1$ \\
$\mathrm{PFn}$ & 65.97 & 5.59 & $\mathrm{Cl}=1.85$ \\
$\mathrm{PFan}$ & 46.63 & 3.05 & $\mathrm{Cl}=7.021$ \\
$\mathrm{PF}$ & 63.16 & 3.28 & $\mathrm{Br}=1.52$ \\
$\mathrm{PFu}$ & 62.1 & 4.85 & $\mathrm{Cl}=12.5$ \\
$\mathrm{PFu}$ & $69.4-69.6$ & $5.6-5.87$ & \\
Poly-1a & 64.23 & 4.02 & \\
Poly-1b & 67.08 & 4.80 & \\
\hline
\end{tabular}

as the oxidizing agent in a medium of $\mathrm{CHCl}_{3}$. These authors

also synthesized conducting composites of polyfuran with acetylene black (AB) by chemical oxidative polymerization of a suspension of $\mathrm{AB}$ in $\mathrm{CHCl}_{3}$ at room temperature using anhydrous $\mathrm{FeCl}_{3}$ as the oxidant.

A combinatorial method employing polymerization parameters intermediate between those typically used to obtain $\mathrm{PFu}$ homopolymers and furan/aniline co-polymers has been explored. In both cases, the oxidant was $\mathrm{FeCl}_{3}$ in $\mathrm{CH}_{3} \mathrm{NO}_{2}$

All of the above chemical methods have been successfully used to obtain $\mathrm{PFu}$ conducting polymers, but, as in the case of electrochemical methods, a general route is difficult to establish.

Elemental analysis has been used by some authors to establish the proportions of the various atoms $[9,14,62,63,68]$ (Table 2) and empirical formulae for $\mathrm{PFu}[14,39,68]$. Tourillon and Garnier [9] published the percentage of doping in $\mathrm{PFu}$ samples, that is four monomeric units per counterion $\left(\mathrm{BF}_{4}{ }^{-}\right)$. However, del Valle deduced that $\mathrm{PFu}$ contains 19 monomeric units per $\mathrm{PF}_{6}{ }^{-}$counterion, five monomeric units per $\mathrm{BF}_{4}{ }^{-}$, and seven monomeric units per $\mathrm{ClO}_{4}{ }^{-}$.

\subsection{Other synthesis methods for PFu conducting polymers}

Some synthesis methods that differ from the electrochemical and chemical ones are summarized in this section.

Polymers formed by the plasma polymerization method are amorphous, hard, tough, insoluble in organic solvents, and resistant to high temperatures as a result of their cross-linked and branched structures.

As regards PFu, Abraham and Sathianandan were the first to publish its plasma polymerization. Kumar grew polymer films in the thickness range $100-500 \mathrm{~nm}$ at a plasma current density of $200 \mathrm{~A} \mathrm{~m}^{-2}$ and a monomer vapor pressure of $26.7 \mathrm{~Pa}$. In this work, electrical studies were carried out on metal-polymer-metal sandwich structures, for which asymmetric $\mathrm{Au}-\mathrm{PFu}-\mathrm{Al}$ and $\mathrm{Au}-\mathrm{PFu}-\mathrm{Ag}$ structures as well as symmetric $\mathrm{Al}-\mathrm{PFu}-\mathrm{Al}$ structures were prepared. The authors surmised that there is a clear dominance of Schottky conduction in the plasma polymerization of furan films.

$\mathrm{X}$-ray irradiation can induce the polymerization of furan overlayers on an $\mathrm{Ru}(001)$ surface at $80 \mathrm{~K}$, as was demonstrated by XPS and UPS techniques .Furan adsorption on Ru (lllll) occurs in a three-dimensional growth mode. These techniques 


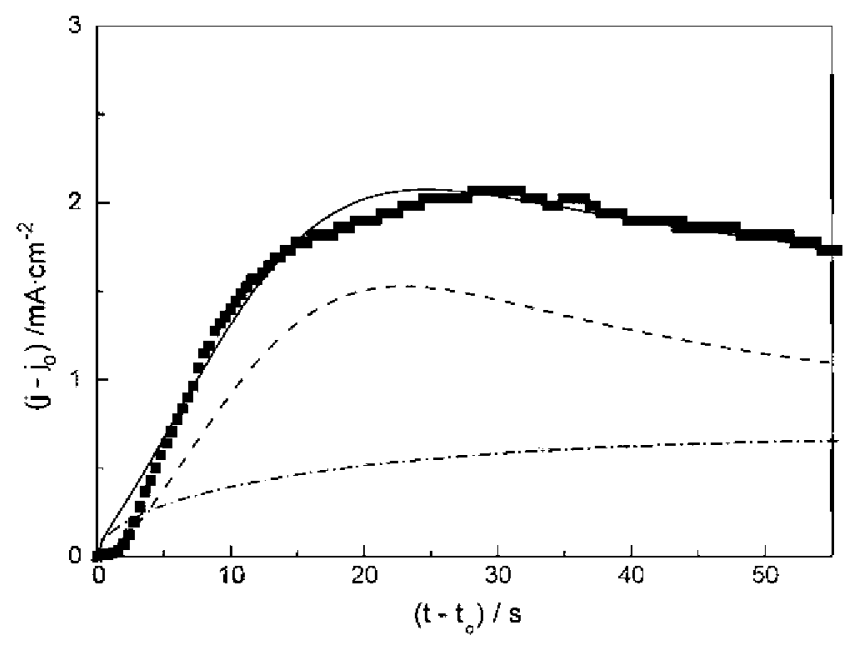

Fig. 1. Plots $f\left(j-j_{0}\right)$ vs. $\left(t-t_{0}\right)$; ( $)$ experimental; $(-)$ mixture of instantaneous and progressive nucleation mechanisms. The contributions progressive $(---)$ and instantaneous (-.- - ) nucleation for $\mathrm{PFu}^{-} \mathrm{ClO}_{4}$ films synthesized in $[\mathrm{Fu}]=\left[\mathrm{NaClO}_{4}\right]=0.1 \mathrm{M}$ in $\mathrm{MeCN}$ at $t_{\mathrm{p}}=1800 \mathrm{~s}$.

were applied to elucidate the structure, orientation, and dissociation of chemisorbed species.

\subsection{Nucleation mechanisms of PFu films}

A general crystallization theory for metal deposition has been developed in order to clarify different aspects of this process. Differences between metal crystallization and polymer formation make it difficult to apply this theory to the generation of polymers due to the fact that their structures are generally amorphous with small crystalline regions.

Electropolymerization processes involve the formation of a new phase through an electrode reaction and require the presence of active sites at the electrode/solution interface where "nuclei" of the new phase can be formed. Nuclei dimensions are dependent on the overpotential or applied current, irrespective of whether the polymer generation is stable or unstable.

Some studies related to $\mathrm{PFu}$ nucleation and growth have been performed and the results indicate that the experimental parameters have a great influence on the process

González-Tejera and Carrillo Ramiro , by analyzing the synthesis chronoamperograms of $\mathrm{PFu}$, established that the nucleation and growth of adherent black PFu perchloratedoped films $\left(\mathrm{PFu} / \mathrm{ClO}_{4}\right)$ on a platinum electrode surface followed a mixture of nucleation mechanisms as a function of the electropolymerization time. Instantaneous and progressive nucleation mechanisms were established, with the progressive contribution prevailing (Fig. 1). Moreover, a three-dimensional growth of hemispherical nuclei under diffusion control was postulated.

With $\mathrm{Bu}_{4} \mathrm{NPF}_{6}$ as the electrolyte, an instantaneous nucleation mechanism with three-dimensional growth at short times has been postulated for potentiostatic PFu synthesis The authors concluded that there were other contributions to the nucleation mechanism.
Table $3 \mathrm{a}$

Electrical conductivity data of PFu conducting films obtained by electrochemical procedures

\begin{tabular}{|c|c|c|}
\hline$\sigma\left(\mathrm{S} \mathrm{cm}^{-1}\right)$ & State & $T(\mathrm{~K})$ (synthesis) \\
\hline $10-80$ & $\mathrm{Bu}_{4} \mathrm{NClO}_{4}$-doped & Room \\
\hline $10^{-11}$ & undoped & - \\
\hline $10^{-5}$ & $\mathrm{ClO}_{4}$-doped & - \\
\hline 1 & $"$ & Room \\
\hline 20 & $\mathrm{BF}_{4}$-doped & Room \\
\hline $\begin{array}{l}{ }^{\mathrm{a}} \mathrm{PFn} 5 \times 10^{-4} \\
{ }^{\mathrm{b}} \mathrm{PFan} 9 \times 10^{-4}\end{array}$ & $\mathrm{Bu}_{4} \mathrm{NClO}_{4}$-doped & Room \\
\hline 10 & $\mathrm{Et}_{4} \mathrm{NClO}_{4}$-doped & Room \\
\hline $\begin{array}{l}8 \times 10^{-1} \\
3 \times 10^{-1}\end{array}$ & $\begin{array}{l}\mathrm{NaClO}_{4} \text {-doped } \\
\mathrm{Bu}_{4} \mathrm{NClO}_{4} \text {-doped }\end{array}$ & $\begin{array}{l}\text { Room } \\
" 1\end{array}$ \\
\hline $\begin{array}{l}2.6 \times 10^{-3} \\
2.4 \times 10^{-2} \\
2.1 \times 10^{-2} \\
9.4 \times 10^{-3}\end{array}$ & $\begin{array}{l}\mathrm{BF}_{4} \text {-doped } \\
/ / \\
" \\
/\end{array}$ & $\begin{array}{l}\text { Room } \\
\text { " } \\
\text { " } \\
\text { " }\end{array}$ \\
\hline $\begin{array}{l}2.98 \times 10^{-6}(\mathrm{ess}) \\
1.49 \times 10^{-5} \text { (s.s) }\end{array}$ & $\mathrm{Li} \mathrm{ClO}_{4}$ & $\begin{array}{l}\text { Room } \\
\text { " }\end{array}$ \\
\hline $\begin{array}{l}4.98 \times 10^{-6}(\mathrm{e} . \mathrm{s}) \\
9.95 \times 10^{-6}(\mathrm{~s} . \mathrm{s})\end{array}$ & $\mathrm{Bu}_{4} \mathrm{NPF}_{6}$-doped & - \\
\hline $\begin{array}{l}9.95 \times 10^{-6}(\mathrm{e} . \mathrm{s}) \\
1.99 \times 10^{-5}(\mathrm{~s} . \mathrm{s})\end{array}$ & $\mathrm{Et}_{4} \mathrm{NBF}_{4}$-doped & - \\
\hline $\begin{array}{l}3.5 \times 10^{-2} \\
2 \times 10^{-2} \\
8 \times 10^{-3}\end{array}$ & $\begin{array}{l}\mathrm{Bu}_{4} \mathrm{NBF}_{4} \text {-doped } \\
\mathrm{Bu}_{4} \mathrm{NBF}_{4} \text {-doped } \\
\mathrm{Bu}_{4} \mathrm{NBF}_{4} \text {-doped }\end{array}$ & $\begin{array}{l}- \\
- \\
\text { Room }\end{array}$ \\
\hline $\begin{array}{l}1.2 \times 10^{-5} \\
4.1 \times 10^{-6}\end{array}$ & $\mathrm{BF}_{4}^{-}$ & Room \\
\hline
\end{tabular}

${ }^{a} \mathrm{PFn}$ anodic coupling of neat furan.

b PFAn, anodic coupling of furan in $\mathrm{MeCN}$, (e.s) film face the electrode surface; (s.s) film face towards the dopant solution.

\section{Electrochemical properties of PFu conducting polymer}

\subsection{Electrical conductivity}

It is known that the conductivity of conducting polymers relies on their ability to be switched between the neutral, nonconducting state and the oxidized, conducting state. In this review, conductivity data for $\mathrm{PFu}$ homopolymers, $\mathrm{PFu}$ composites, PFu co-polymers, and PFu bipolymers are listed and compared.

It is difficult to establish a fixed value for PFu conductivity, since different conductivity values are obtained depending on the experimental synthesis conditions (see Tables $3 a$ and $3 b$ ). Low electrical conductivities may be attributed to short conjugation lengths, as well as the ring-opening reaction, the degree of cross-linking, and defects in the lattice as a result of different morphologies.

Electrochemically obtained PFu homopolymers display various conductivities ranging from $10^{-6}$ to $80 \mathrm{~S} \mathrm{~cm}^{-1}$ in the doped state (see Table 3a), the electrical conductivity of undoped $\mathrm{PFu}$ being $10^{-11} \mathrm{~S} \mathrm{~cm}^{-1}$ in vacuo. Higher conductivities of 20 and $80 \mathrm{~S} \mathrm{~cm}^{-1}$ were reported 
Table $3 b$

Electrical conductivity data of PFu conducting films obtained by chemical procedures

\begin{tabular}{cll}
\hline$\sigma\left(\mathrm{S} \mathrm{cm}^{-1}\right)$ & State & $T(\mathrm{~K})$ (synthesis) \\
\hline $1.2 \times 10^{-5}$ & $\mathrm{FeCl}_{3}$ doped & 293 \\
$1.44 \times 10^{-5}$ & Undoped & Room \\
$1.44 \times 10^{-5}$ & Undoped & Room \\
$1.44 \times 10^{-5}$ & Undoped & Room \\
$1.44 \times 10^{-5}$ & Undoped & Room \\
$2.93 \times 10^{-5}$ & " & " \\
$10^{-6}$ & Undoped & Room \\
$1.44 \times 10^{-5}$ & Undoped & Room \\
$1.3 \times 10^{-6}$ & - & Room \\
$1.3 \times 10^{-6}$ & - & 298 \\
$10^{-9}$ & Undoped & 398 \\
$10^{-5}$ & $\mathrm{I}_{2}$-doped & 333 \\
$5 \times 10^{-6}$ & " & - \\
$10^{-6}-10^{-5 \mathrm{~d}}$ & Undoped & Room \\
$\sim 10^{-3 \mathrm{~b}}$ & " & " \\
$6.2 \times 10^{-9 \mathrm{c}}$ & I -doped & " \\
$1.8 \times 10^{-9 \mathrm{c}}$ & " & \\
$10^{-4}-10^{-3}$ & Undoped & Room
\end{tabular}

a $\mathrm{PFu} . \mathrm{Cl}$ obtained with $\mathrm{FeCl}_{3}$ in $\mathrm{CHCl}_{3}$.

b PFuCl.E, polymers submitted to extraction with boiling absolute ethanol.

c PFu.Cl.I and PFu.An.I (polymers obtained with $\mathrm{FeCl}_{3}$ in $\mathrm{MeCN}$ ) suspended in an $\mathrm{I}_{2}$ solution.

tively. The reasons for these higher values could be that in the electrolytic medium had a water content of about $10^{-2} \mathrm{M}$, while Nalwa used furan monomer without any further purification and therefore the impurities could have led to the increased conductivity value. The broad range is an indication that the experimental conditions greatly influence the $\pi$-conjugated system and the doping level of the polymer backbone.

Conductivities are also dependent on the dopant anion. With tetraalkylammonium salts , conductivities range from $10^{-6}$ to $80 \mathrm{~S} \mathrm{~cm}^{-1}$ at room temperature. With $\mathrm{BF}_{4}$ , the higher value of $20 \mathrm{~S} \mathrm{~cm}^{-1}$ reported was obtained. When the electrolyte was $\mathrm{AgClO}_{4}$ $\mathrm{NaClO}_{4}$ , and $\mathrm{LiClO}_{4}$, the conductivities changed from $10^{-5}$ to $1 \mathrm{~S} \mathrm{~cm}^{-1}$ depending on the degree of hydration (see Fig. 2) as water may affect the potential barrier. In the case of a stainless steel electrode the $\sigma$ value was around $10 \mathrm{~S} \mathrm{~cm}^{-1}$, depending on the pressure applied to the electrodes.

The conductivities of PFu samples obtained by chemical methods typically vary from $10^{-5}$ to $10^{-6} \mathrm{~S} \mathrm{~cm}^{-1}$ (see Table $3 \mathrm{~b}$ ) , although values of $10^{-9}$ and $10^{-3} \mathrm{~S} \mathrm{~cm}^{-1}$ have been measured

It is interesting to note that the conductivity of PFu obtained chemically with $\mathrm{FeCl}_{3}$ in $\mathrm{CHCl}_{3}$ was reported to be $10^{-6} \mathrm{~S} \mathrm{~cm}^{-1}$ which is one order of magnitude lower than the value reported by Sari

In both studies, the chemical polymerization was carried out in a non-aqueous medium $\left(\mathrm{CHCl}_{3}\right)$ with $\mathrm{FeCl}_{3}$ as the chemical oxidant, but the polymerization took place at $0^{\circ} \mathrm{C}$ in a cold water bath, while in it was performed at $24^{\circ} \mathrm{C}$. The only differences

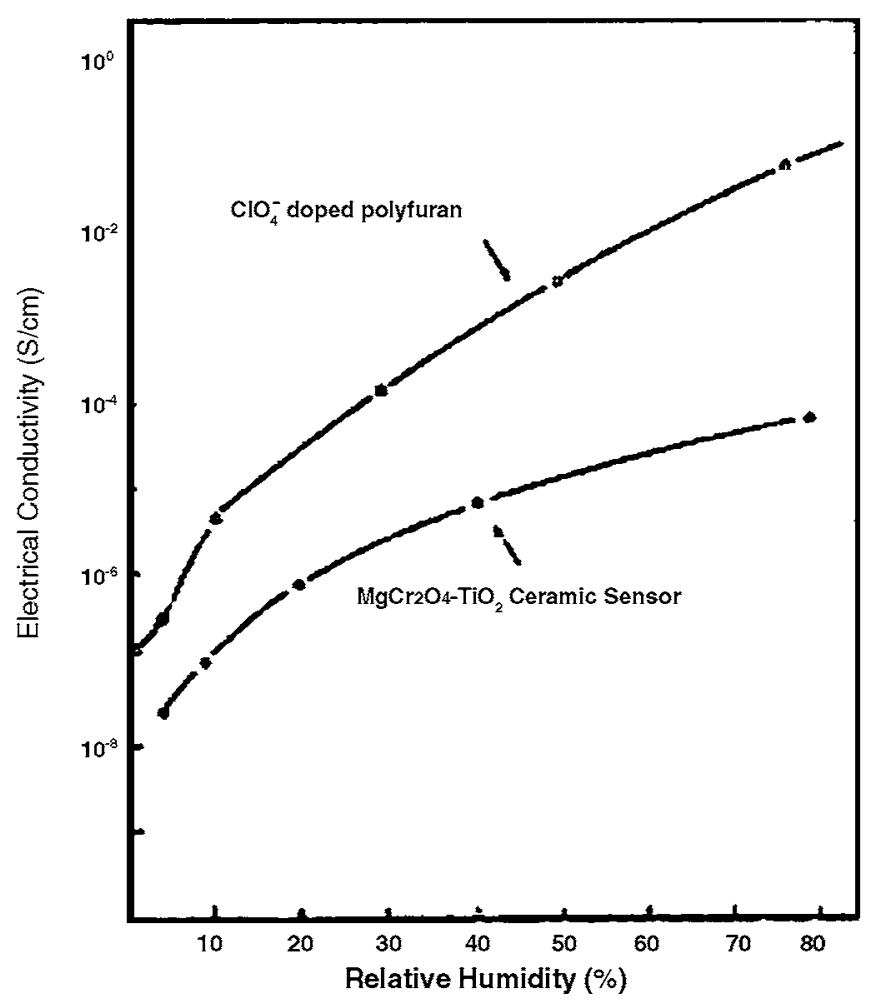

Fig. 2. Dependence of electrical resistivity of polyfuran on humidity . (Figure reprinted with permission Society of Applied Physics). Copyright 1984. The Japanese

between the two syntheses were the temperature and the furan concentration.

Only PFu homopolymers electrosynthesized with $\mathrm{Bu}_{4} \mathrm{NClO}_{4}$ or $\mathrm{Bu}_{4} \mathrm{NBF}_{4}$ have displayed the higher $\sigma$ values (see Tables $3 a$ and $3 b$ ).

In an attempt to improve the electrical conductivity of $\mathrm{PFu}$ and therefore its technological applications, many authors have tried to synthesize homogeneous and heterogeneous composite materials based on it. Relevant data are listed in Table 4.

$\mathrm{PFu}$ composites based on poly(o-toluidine) (POT) and $\mathrm{PFu}$, obtained by changing the synthesis order and the dopant anion, have been fabricated, as indicated in Table 4 . The same group obtained $\mathrm{PFu}$ composite materials by the use of poly (2halogenoaniline)s such as poly(2-iodoaniline) (P2IAn) poly(2-chloroaniline) (P2ClAn) , poly(2-fluoroaniline) (P2FAn) , and poly (2-bromoaniline) (P2BrAn)

with different proportions of poly(2-halogenoaniline)s and $\mathrm{PFu}$ in the composites. The conductivities of the composites proved to be higher than those of the homopolymers. As the poly(2-halogenoaniline) content was increased, the conductivity increased . The P2IAn/PFu composites were better conductors than their PFu/P2IAn counterparts, which may be attributed to the greater ease with which $\mathrm{PFu}$ chains may be introduced into the P2IAn backbone. the authors noted that the conductivities of the composite samples tended to change according to the order of synthesis.

PFu nanocomposites have been prepared with nanodimensional $\mathrm{Al}_{2} \mathrm{O}_{3}$ and montmorillonite clay, and these displayed conductivities of $10^{-7}$ and $10^{-8} \mathrm{~S} \mathrm{~cm}^{-1}$, respectively (Table 4). 
Table 4

Electrical conductivity data of PFu composites conducting films obtained by chemical or electrochemical methods

\begin{tabular}{|c|c|c|}
\hline$\sigma\left(\mathrm{S} \mathrm{cm}^{-1}\right)$ & State & $T(\mathrm{~K})$ (synthesis) \\
\hline $\begin{array}{l}\text { PFu/POT: } 6.6 \times 10^{-2} \\
\text { POT/PFu: } 1.9 \times 10^{-5} \\
\text { POT/PFu }(1: 1): 1.9 \times 10^{-5}\end{array}$ & $\begin{array}{l}\left(\mathrm{NH}_{4}\right)_{2} \mathrm{~S}_{2} \mathrm{O}_{8} \text {-doped } \\
\mathrm{FeCl}_{3} \text {-doped }\end{array}$ & $\begin{array}{l}293 \\
11 \\
\prime \prime\end{array}$ \\
\hline $\begin{array}{l}\text { PFu/P2IAn: } \sim 10^{-5} \\
\text { P2IAn/PFu: } 1.02 \times 10^{-3} \rightarrow 7.48 \times 10^{-5}\end{array}$ & Undoped & 293 \\
\hline $\begin{array}{l}\text { PFu/P2ClAn: } 3.44 \times 10^{-5} \rightarrow 1.33 \times 10^{-3} \\
\text { P2C1An/PFu: } \sim 10^{-3}\end{array}$ & Undoped & 293 \\
\hline $\begin{array}{l}\text { PFu/P2FAn: } 1.84 \times 10^{-4} \rightarrow 6.04 \times 10^{-5} \\
\text { P2FAn/PFu: } \sim 10^{-5}\end{array}$ & Undoped & 293 \\
\hline $\begin{array}{l}\mathrm{P} 2 \mathrm{BrAn}\left(\mathrm{FeCl}_{3}\right) / \mathrm{PFu}\left(\mathrm{SbCl}_{3}\right): 7.89 \times 10^{-5} \\
\mathrm{P} 2 \mathrm{BrAn}\left[\left(\mathrm{NH}_{4}\right)_{2} \mathrm{~S}_{2} \mathrm{O}_{8} / \mathrm{PFu}\left(\mathrm{SbCl}_{3}\right): 8.33 \times 10^{-5}\right.\end{array}$ & Doped & Room \\
\hline $\begin{array}{l}\mathrm{PFu} / \mathrm{Al}_{2} \mathrm{O}_{3}: 10^{-7} \\
\mathrm{PFu} / \mathrm{MMT}: 10^{-8}\end{array}$ & Undoped & 293 \\
\hline $\mathrm{PFu} / \mathrm{AB} \approx 10^{-3}$ & Undoped & Room \\
\hline $\begin{array}{l}\mathrm{PFu} / \mathrm{P} 2 \mathrm{FAn}: 1.46 \times 10^{-4} \\
\mathrm{P} 2 \mathrm{FAn} / \mathrm{PFu}: 1.50 \times 10^{-5}\end{array}$ & $\begin{array}{l}\text { Doped } \\
\text { " }\end{array}$ & $\begin{array}{l}\text { Room } \\
\text { "l }\end{array}$ \\
\hline $\mathrm{PFu} / \mathrm{P} 2 \mathrm{BrAn}: 1.32 \times 10^{-5}$ & $"$ & $" 1$ \\
\hline P2BrAn/PFu: $8.33 \times 10^{-5}$ & " & $" 1$ \\
\hline $\mathrm{PFu} / \mathrm{P} 2 \mathrm{ClAn}: 9.77 \times 10^{-3}$ & $"$ & " \\
\hline $\mathrm{P} 2 \mathrm{ClAn} / \mathrm{PFu}: 3.21 \times 10^{-2}$ & " & $" 1$ \\
\hline PFu/P2IAn: $2.77 \times 10^{-3}$ & $"$ & $" 1$ \\
\hline P2IAn/PFu: $5.78 \times 10^{-5}$ & $" 1$ & $" 1$ \\
\hline
\end{tabular}

Ballav and Biswas synthesized a composite of polyfuran and acetylene black, $\mathrm{PFu} / \mathrm{AB}$, the conductivity of which was of the order of $10^{-3} \mathrm{~S} \mathrm{~cm}^{-1}$.

All of the above PFu composite materials have electrical conductivities in the range $10^{-2}-10^{-8} \mathrm{~S} \mathrm{~cm}^{-1}$. Among these composites, the highest conductivities were found for $\mathrm{P} 2 \mathrm{ClAn} / \mathrm{PFu}$

Co-polymers show increased conductivities, probably due to an increase in the stability of the polymer and a higher degree of backbone conjugation. Their reported conductivities range from $10^{-2}$ to $10^{-4} \mathrm{~S} \mathrm{~cm}^{-1}$ (see Table 5). To this end, McConnell et al. chemically synthesized $\mathrm{PFu}$ with $2 \%$ pyrrole $(\mathrm{PFu}-\mathrm{PPy})$ and $\mathrm{PFu}$ with $2 \%$ thiophene (PFu-PTh). As mentioned in Section 2.2, the same group prepared co-polymers of PFu with $1-5 \%$ of pyrrole or thiophene The electrical conductivities of the co-polymers were found to be directly proportional to the amount of thiophene or pyrrole introduced into the PFu matrix (see Table 5). Spectral data confirmed that the increased conductivity could be attributed to an increase in the stability of the polymer and a higher degree of backbone conjugation.

The co-polymerization of $\mathrm{Fu}$ and 3-methylthiophene has also been performed and the product thus obtained showed one of the highest conductivities. When the polymerization potential was too high, the conjugated structure of the co-polymer was destroyed and a decrease in its conductivity was observed. In

Table 5

Electrical conductivity data of PFu co-polymers conducting films obtained by chemical or electrochemical methods

\begin{tabular}{|c|c|c|}
\hline$\sigma\left(\mathrm{S} \mathrm{cm}^{-1}\right)$ & State & $T(\mathrm{~K})$ (synthesis) \\
\hline $\begin{array}{l}\text { PFu-PTh: } 2.1 \times 10^{-4} \\
\text { PFu_Ppy: } 1.7 \times 10^{-3}\end{array}$ & $\begin{array}{l}- \\
-\end{array}$ & $\begin{array}{l}\text { Room } \\
\text { "1 }\end{array}$ \\
\hline $\begin{array}{l}\text { PFu/PMTh: } \\
28 \times 10^{-2}(1.1 \mathrm{~V}) \\
36 \times 10^{-2}(1.2 \mathrm{~V}) \\
25 \times 10^{-2}(1.3 \mathrm{~V}) \\
12 \times 10^{-2}(1.4 \mathrm{~V}) \\
7 \times 10^{-2}(1.5 \mathrm{~V})\end{array}$ & $\begin{array}{l}\mathrm{Bu}_{4} \mathrm{NBF}_{4} \text {-doped } \\
" 1 \\
" 1 \\
" 1 \\
" 1\end{array}$ & $\begin{array}{l}\text { Room } \\
\text { "1 } \\
\text { " } \\
" 1 \\
\text { " } \\
\text { " }\end{array}$ \\
\hline $\begin{array}{l}\mathrm{PFu} / 1 \% \rightarrow 5 \% \mathrm{Th}: \\
7.8 \times 10^{-5}, 2.1 \times 10^{-4} \rightarrow 9.5 \times 10^{-4} \\
\mathrm{PFu} / 1 \% \rightarrow 5 \% \mathrm{Py}: \\
7.3 \times 10^{-4}, 1.5 \times 10^{-3}, 9.2 \times 10^{-3}, 8.6 \times 10^{-3}, 3.2 \times 10^{-2}\end{array}$ & $\begin{array}{l}\text { Undoped } \\
\text { " }\end{array}$ & $\begin{array}{l}298 \\
11\end{array}$ \\
\hline
\end{tabular}

Values in parentheses indicate the electropolymerization potential. 
Table 6

Electrical conductivity data of $\mathrm{PFu}$ bipolymers conducting films obtained by chemical or electrochemical methods

\begin{tabular}{|c|c|c|}
\hline$\sigma\left(\mathrm{S} \mathrm{cm}^{-1}\right)$ & State & $T(\mathrm{~K})$ (synthesis) \\
\hline $\begin{array}{l}\text { PFu/PTh: } 2.48 \times 10^{-4} \text { (e.s), } 9.95 \times 10^{-3} \text { (s.s) } \\
\text { PTh/PFu: } 3.98 \times 10^{-4} \text { (e.s), } 3.48 \times 10^{-6} \text { (s.s) }\end{array}$ & $\mathrm{ClO}_{4}$-doped & Room \\
\hline $\begin{array}{l}\text { PFu/PTh: } 2.79 \times 10^{-3}(\mathrm{e} . \mathrm{s}), 4.98 \times 10^{-4}(\mathrm{s.s}) \\
\text { PTh/PFu: } 1.14 \times 10^{-3}(\mathrm{e} . \mathrm{s}), 4.47 \times 10^{-6}(\mathrm{s.s}) \\
\text { PFu/PTh: } 3.38 \times 10^{-3}(\mathrm{e} . \mathrm{s}), 1.24 \times 10^{-2}(\mathrm{~s} . \mathrm{s}) \\
\text { PTh/PFu: } 5.87 \times 10^{-3}(\mathrm{e} . \mathrm{s}), 9.45 \times 10^{-4}(\mathrm{s.s})\end{array}$ & $\begin{array}{l}\mathrm{Bu}_{4} \mathrm{NPF}_{6} \text {-doped } \\
\mathrm{Et}_{4} \mathrm{NBF}_{4} \text {-doped }\end{array}$ & - \\
\hline
\end{tabular}

(e.s) film face the electrode surface; (s.s) film face towards the dopant solution.

Table 5, values in parentheses indicate the electropolymerization potentials.

The research group of $\mathrm{M}$. Talu et al. electropolymerized bilayers of thiophene and polyfuran with different dopant anions with the aim of expanding the range of technological applications of these conducting systems The latter work revealed the great influence of the supporting electrolyte on the structures and hence on the conductivities of the bipolymers. These electrical conductivity data are included in Table 6 and can be seen to be in the same range as those of co-polymers.

From Tables 4-6, it can be deduced that electrical conductivities do not depend on the host component of the material generated. Therefore, the $\pi$-conjugated system remains unaffected.

\subsection{Electrochemical behavior}

Cyclic voltammetry has been employed for numerous basic studies of electrochemical systems and is a powerful tool in the study of electrode reaction mechanisms.

Zotti published the cathodic response of $\mathrm{PFu}$ films obtained from 2,5-dibromofuran in the presence of an excess of a nickel complex (Table 1). They showed the oxidation cyclic voltammograms after nickel extraction at different scan rates and the inactive response with repetitive reduction cycles. A reversible behavior was found, with a reversible charge of $6 \mathrm{mC} \mathrm{cm}^{-2}$ in the PFu obtained by anodic coupling of neat furan ( $\mathrm{PFn}$ ) (Table 1). The redox behavior revealed a reversible oxidation cycle at $0.45 \mathrm{~V}$, stable to oxidation up to $0.9 \mathrm{~V}$, with a reversible charge density of $14 \mathrm{mC} \mathrm{cm}^{-2}$. When the electrode was submitted to continuous cycling, a progressive deactivation attributed to proton donors in the medium was observed. The $\mathrm{PFu}$ redox behavior was accompanied by a change in color from yellow to green and finally to dark blue.

Glenis deduced a homogeneous and relatively narrow distribution of conjugation lengths along the polymer chains from the $\mathrm{CV}$ trace. They described only one anodic peak, which was sharper than the cathodic peak, having a width at half-height of $50 \mathrm{mV}$. On the basis of spectroscopic evidence, they suggested that $\mathrm{ClO}_{4}{ }^{-}$and $\mathrm{PF}_{6}{ }^{-}$as dopants generated a poorly defined nonconjugated material. They also concluded that one electron was removed from polymer segments containing four furan units, as has been observed for other conducting polymers.

A detailed cyclic voltammetric study of perchlorate-doped $\mathrm{PFu}$ films was carried out by González-Tejera
The influences of monomer and electrolyte concentrations, electrodeposition potential (see Fig. 3), increasing positive and negative potential, scan rate, and continuous cycling were analyzed. They found that all the redox processes were irreversible, the oxidation and reduction processes being controlled by superficial capacitive charge transfer and by diffusion, respectively. When $\mathrm{PFu}$ films were submitted to continuous charge-discharge processes, the electroactivity and degradation varied in dependence on the monomer concentration.

Less well-defined peaks were seen when $\mathrm{PFu}$ films were obtained in a binary solvent system and cycled in nonaqueous and aqueous media. The redox activity was almost totally lost in an aqueous medium when it had been cycled. The rate of loss of redox activity increased with increasing amount of water in the MeCN solutions. Likewise, the oxidation processes became irreversible, probably due to the destruction of conjugated structures, although Raman spectroscopy showed that most of the conjugated structures in $\mathrm{PFu}$ remained intact even after it had been cycled 100 times in aqueous solution. However, Tirkeş and Önal established that $\mathrm{PFu}$ films lost their electroactivity in the presence of water.

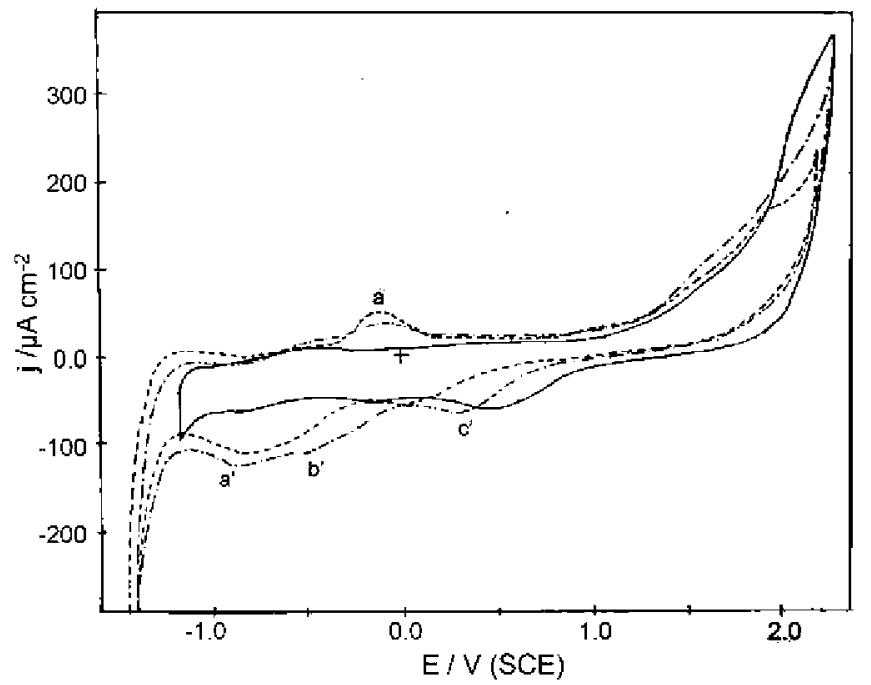

Fig. 3. CVs of black $\mathrm{PFu} / \mathrm{ClO}_{4}$ films synthesized at $[\mathrm{Fu}]=2\left[\mathrm{NaClO}_{4}\right]=0.4 \mathrm{M}$ at $E_{\mathrm{p}}=2.1 \mathrm{~V}(-\cdot-\cdot-), E_{\mathrm{p}}=2.3 \mathrm{~V}(---)$ and a bare Pt electrode (-) in $0.2 \mathrm{M}$ $\mathrm{NaClO}_{4}+\mathrm{MeCN}$. Potential scan rate, $\nu=30 \mathrm{mV} \mathrm{s}^{-1}$. Peak $a$ is an oxidation process and waves $a^{\prime}, b^{\prime}$ and $c^{\prime}$ are reduction ones [20]. (Figure reprinted with permission from ref. [20]. Copyright 2002. Springer Science and Business Media). 


$$
\underset{\mathrm{H}_{2} \mathrm{C}}{\mathrm{C}}-\underset{\mathrm{O}}{\mathrm{C}}-\mathrm{C}=
$$

(a)

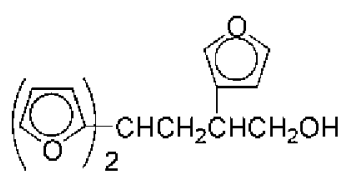

(c)

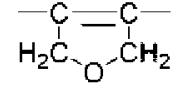

(b)

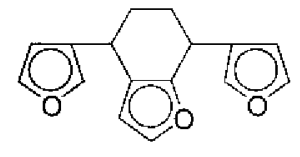

(d)

Scheme 2. Structural units found in polyfuran films, $\mathrm{PFu}$ :

Kabasakaloğlu

studied the formation of $\mathrm{PFu} / \mathrm{PTh}$ bipolymer; no significant peaks indicating defined redox processes were observed and the broad peaks were identical to those obtained for thiophene oxidation. On the contrary, on changing the coverage order, PTh/PFu films showed different behavior; the peak potentials did not correspond to those of PTh and $\mathrm{PFu}$, indicating that $\mathrm{PTh} / \mathrm{PFu}$ might be a co-polymer.

\section{Structural properties}

In this section, some techniques related to structure determination of the polymers, such as vibrational, UV/Vis, X-ray photoelectron, ESR, and NMR spectroscopies, are covered.

\subsection{Vibrational spectroscopy}

Vibrational spectroscopy is a powerful method for determining not only the structural properties of the polymer chain, but also the electronic properties, which are related to the conductivity of the material.

IR and Raman spectroscopies have been used to determine the structural properties of PFu

From these studies, the authors concluded that this polymer contained the repeat units shown in Scheme 2. The influence of dopant ions was also investigated

Zotti et al. reported for the first time the IR spectra of PFu samples obtained by different synthetic methods; they found that in polymers produced by anodic coupling (PF), bands attributable to $\nu(\mathrm{C}=\mathrm{O})$ and aliphatic and aromatic $\nu(\mathrm{C}-\mathrm{H})$ stretching vibrations could be seen; the relative intensities of the aliphatic and aromatic bands varied depending on whether neat furan (PFn) or furan solution (PFan) had been used. In the first case, the IR spectrum (which matched that of acid-polymerized $\mathrm{PFu}$ ), indicated that aromatic monomer units (Scheme 3(a)) were in the minority in a structure crowded with several dihydro(Scheme 3(b)) and tetrahydrofuran moieties (Scheme 3(c)), as well as open segments, as suggested by Lamb et al. [63] (Scheme 3(d)). In the spectrum of the polymer produced by the cathodic route no signal in the region $2900-2800 \mathrm{~cm}^{-1}$ was found. Besides, the presence of $v(\mathrm{C}-\mathrm{H})$ at $3100 \mathrm{~cm}^{-1}$ indicated that the material produced was polyconjugated $\mathrm{PFu}$.

Hernández et al. by taking into account the vibrational spectra of the oligomeric compounds and their previous semi-empirical MNDO calculations, assigned the vibrational spectrum of pristine $\mathrm{PFu}$. In another work they analyzed the dependence of $\pi$-electron delocalization on chain length. Their observations supported a hypothesis made on the basis of photoexcitation experiments that their polymer sample had a bimodal distribution of conjugation lengths due to at least two components.

The effect of the electrolyte on the structure of $\mathrm{PFu}$ was studied by Glenis Due to vibronic coupling of the delocalized positive charges in the oxidized polymer with the skeletal stretching vibration of the carbon backbone, the IR bands of the doped material were broadened and shifted to lower frequencies (see Fig. 4). The presence of $\nu(\mathrm{C}=\mathrm{O})$ and aliphatic $\nu(\mathrm{C}-\mathrm{H})$ stretching modes confirmed that significant structural changes and serious disruption of the expected conjugation length had taken place. The authors speculated that one potential pathway for ring-opening could be nucleophilic attack at the positively charged $\alpha$-carbon centers by dopant and/or water.

Carrillo et al. studied the influence of the deposition potential the electrodeposition time and the relationship between the monomer and electrolyte concentrations together with the electropolymerization overpotential , on the synthesis of $\mathrm{PFu} / \mathrm{ClO}_{4}$-doped conducting polymer (see Fig. 5). In these studies, FTIR spectra were indicative of similar structures to those presented in Schemes 3(a,b) and 4(a,b) due to the pres-

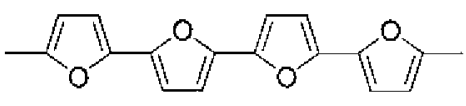

(a)

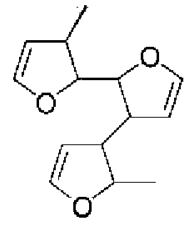

(b)

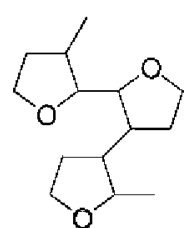

(c)<smiles>CC(=O)CCC(=O)C(=O)CCC(C)=O</smiles>

(d) 


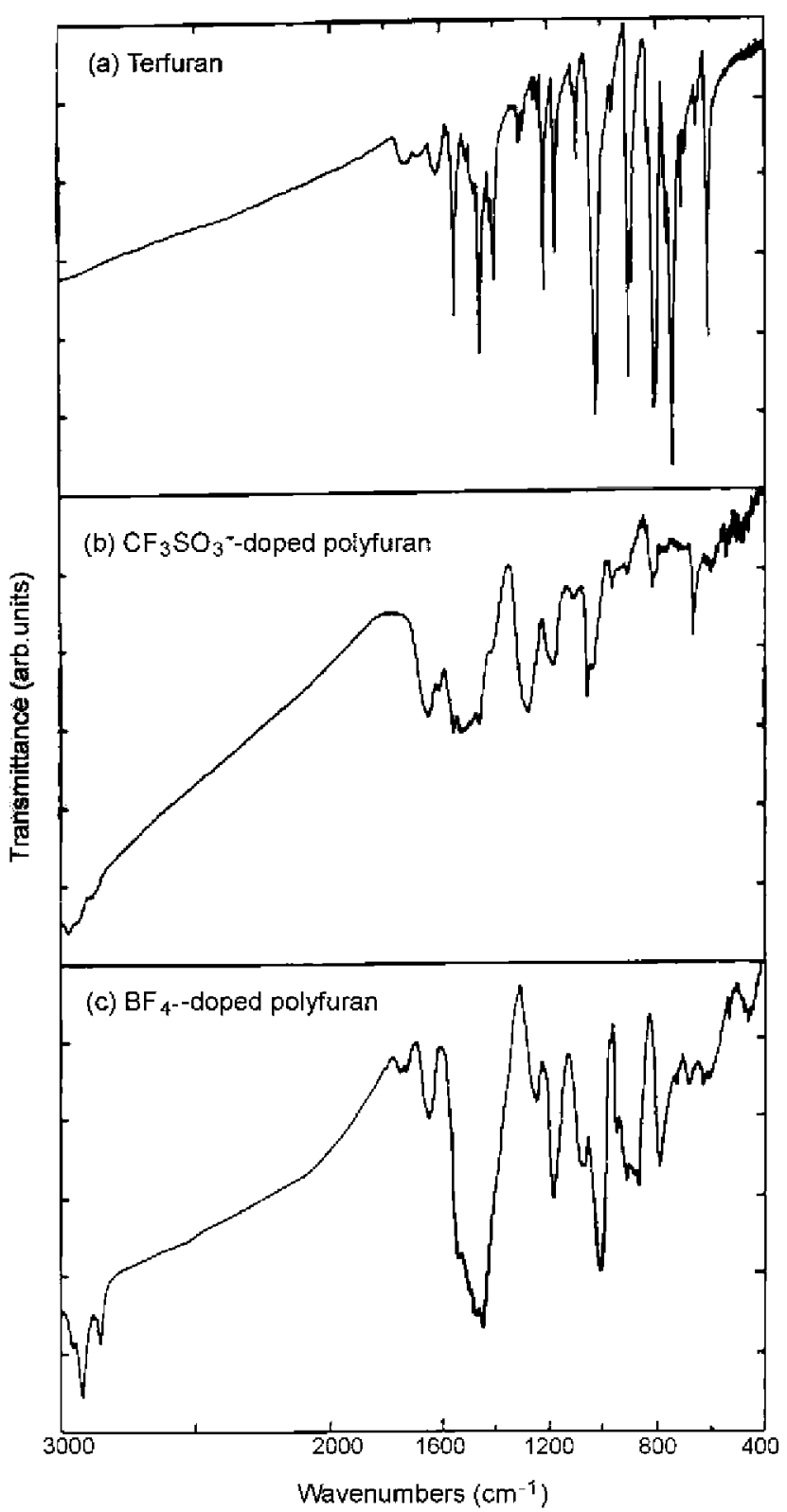

Fig. 4. Infrared transmission spectra of (a) terfuran; (b) $\mathrm{CF}_{3} \mathrm{SO}_{3}{ }^{-}$doped polyfuran; and (c) $\mathrm{ClO}_{4}{ }^{-}$-doped polyfuran from powder pressed in $\mathrm{KBr}$. (Figure Society).

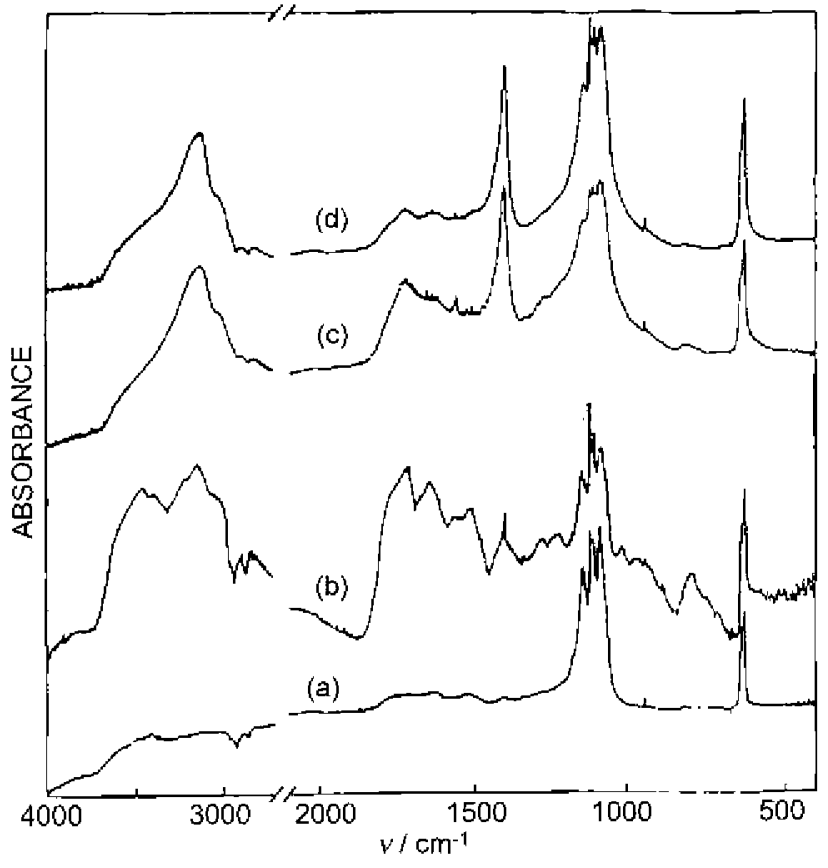

Fig. 5. FTIR spectra of $\mathrm{PFu} / \mathrm{ClO}_{4}$ films $\left(4000-400 \mathrm{~cm}^{-1}\right)$ synthesized at $2.1 \mathrm{~V}$ : (a) $[\mathrm{Fu}]=\left[\mathrm{NaClO}_{4}\right]=0.1 \mathrm{M} ;$ (b) $[\mathrm{Fu}]=\left[\mathrm{NaClO}_{4}\right]=0.2 \mathrm{M}$; (c) $[\mathrm{Fu}]=2\left[\mathrm{NaClO}_{4}\right]=0.2 \mathrm{M}$; and $(\mathrm{d})[\mathrm{Fu}]=2\left[\mathrm{NaClO}_{4}\right]=0.4 \mathrm{M}$ film. (Figure reprinted with permission from ref. [81]. Copyright 2000 . John Wiley \& Sons, Inc.).

ence of $\mathrm{C}=\mathrm{O}$ and aliphatic $\mathrm{C}-\mathrm{H}$ stretching bands at all deposition potentials studied, caused by simultaneous non-oxidative furan polymerization and electrostatic interactions between the counterions and aromatic rings. The influence of the temperature on film degradation was also studied by FTIR spectroscopy It was found that the structure was partially conserved until about $210^{\circ} \mathrm{C}$.

From FTIR spectroscopic studies, Tirkeş and Önal established that the $\mathrm{Fu}$ rings of $\mathrm{PFu}$ obtained from an $\mathrm{MeCN} / \mathrm{BF}_{3} / \mathrm{DEE}$ mixture were not affected during electrochemical polymerization.

Wan analyzed the degradation of doped $\mathrm{PFu}$ in different media by FTIR and Raman spectroscopies; they found that it was controlled by two different degradation mechanisms, cross-linking and nucleophilic attack, from which it was concluded that only positively charged sites in the poly-

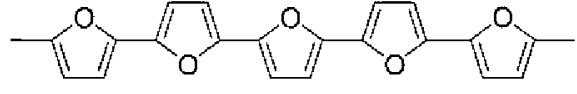

(a)<smiles>C=C1C=COC(C)(C)C1C</smiles>

(b)<smiles>CC1(C)OC(=O)C(C)(C)C1c1ccco1</smiles>

(c)

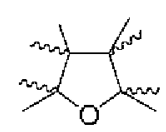

(d)<smiles></smiles>

(e)

Scheme 4. Polyfuran structures proposed 


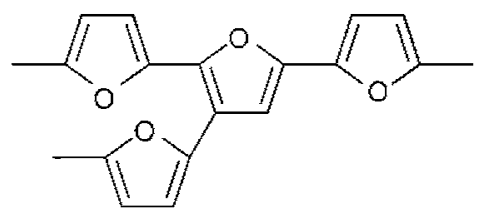

Scheme 5. Structure of plasma-polymerized furan [83].

mer chains were attacked during the electrochemical process. They found through the application of SERS and FTIR reflection techniques, that the molecular arrangement of $\mathrm{PFu}$ extended parallel to the electrode surface. The same authors

used vibrational spectroscopy to estimate the composition of a film obtained by electrochemical co-polymerization of furan and pyrrole and to confirm that co-polymerization had indeed occurred.

An IR analysis conducted by Benvenuti indicated that the polymeric product was the result of two distinct processes, one of them causing oxidative coupling to afford repeating aromatic units and the other involving cationic species responsible for the presence of non-aromatic units, and they proposed sequences of aromatic furan ring units (Scheme 4(a)) randomly distributed along the backbone of a more complex structure that also incorporated dihydro- and tetrahydrofurylene units (Scheme 4(b), (c), and (d)) as well as open-chain units (Scheme 4(e)).

McConnell et al. [67] used UV/Vis, IR, NMR, and ESR spectroscopies to characterize PFu. They assigned the IR band at $640 \mathrm{~cm}^{-1}$ to head-to-tail coupling of the carbon backbone. This same conclusion about the coupling of the radical cations was reached by Demirboğa and Önal based on the FTIR spectrum of electropolymerized PFu.

From the IR spectrum of $\mathrm{PFu}$ obtained by polymerizing monomeric furan in a radiofrequency discharge plasma, Kumar [83] inferred that the structure of the plasma-polymerized furan had been formed following deprotonation (see Scheme 5). the authors speculated on whether mixing $\mathrm{PFu}$ with $\mathrm{P} 2(\mathrm{Cl}$, I or F)An would affect the formation of intermolecular interactions between the two polymers and hence the structure of the obtained composites.

Novel furan compounds incorporating phenyl rings separated by alkene spacers have been chemically synthesized The polymer spectra showed strong $\mathrm{C}=\mathrm{O}$ stretching absorption bands, suggesting that furan rings had been opened.

Electrochemical co-polymerization of furan and 3methylthiophene, at different polymerization potentials, was carried out by Li They used FTIR spectroscopy to confirm that 3-methylthiophene units had been incorporated into the co-polymer chain and that the amount of these incorporated units increased with the preparation potential. The quality of the doped PFu was improved and ring opening was minimized by the introduction of small amounts of pyrrole or thiophene into the polymer matrix [43].

FTIR spectroscopy has been used to confirm the formation of $\mathrm{PFu}$ in the interlayer space of the host material during the intercalative oxidative polymerization of terfuran in $\mathrm{FeOCl}$ [66] and the intercalation of $\mathrm{PFu}$ in montmoril-

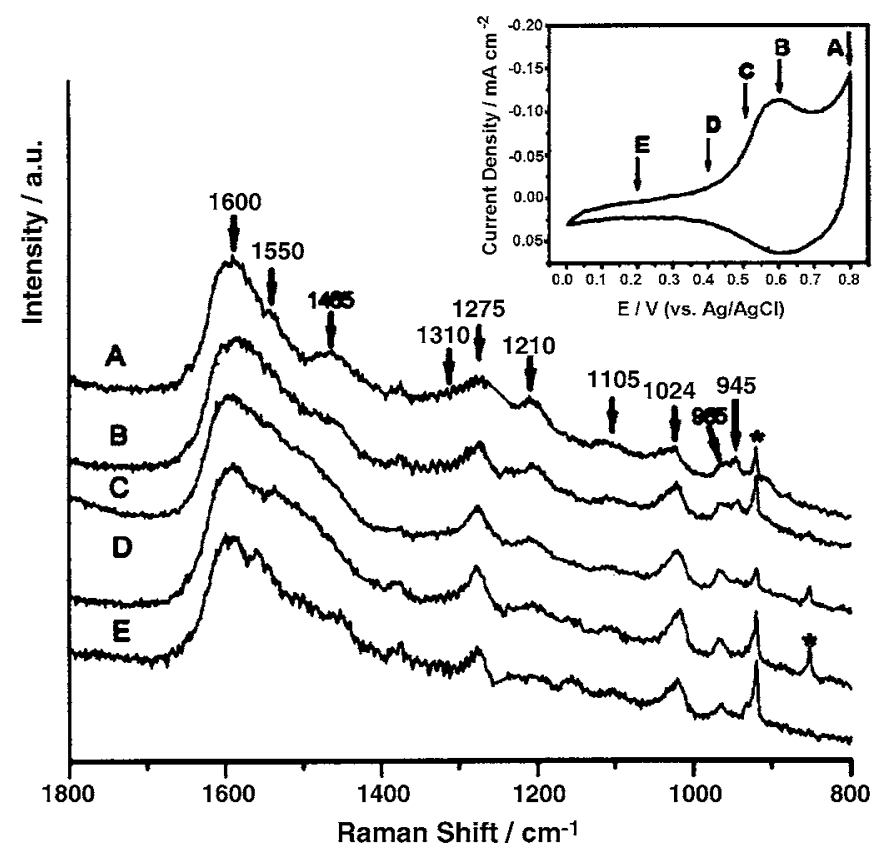

Fig. 6. In-situ Raman spectra recorded at different applied potentials (asterisks indicate solvent): $800 \mathrm{mV}$ (spectrum A), $600 \mathrm{mV}$ (spectrum B), $500 \mathrm{mV}$ (spectrum C); $400 \mathrm{mV}$ (spectrum D), and $200 \mathrm{mV}$ (spectrum E). (Figure reprinted with permission from ref. [27]. Copyright 2004. American Chemical Society).

lonite clay (MMT) _ _ and acetylene black_ composite systems.

Ogawa et al. analyzed the FTIR spectrum of a $\mathrm{PFu}$-titanium oxide composite to investigate the ability of this system to fix atmospheric nitrogen.

Electrochemically prepared doped and de-doped PFu films have been studied by resonance Raman, in situ Raman spectroelectrochemical (see Fig. 6), confocal Raman microscopy, and surface-enhanced Raman scattering techniques The experimental Raman spectrum of PFu in the doped state was different from that in the neutral state. Theoretical Raman spectra of doped oligofurans were calculated and showed satisfactory agreement with the recorded spectra.

\subsection{UV spectroscopy}

The optical properties of conjugated polymers are generally characterized by a wide absorption band due to intrinsic energetic disorder in these polymers. A broad absorption means a wider distribution of the conjugation lengths in the polymer ${ }_{\mathrm{L}} \ldots \ldots$. Wan et al. [22] found that in neutral PFu the band gap was about $2.07 \mathrm{eV}$, smaller than the calculated one $(6.5 \mathrm{eV})$. Oshawa et al. [11] studied the absorption spectra of $\mathrm{PFu}$ in the doped and undoped states, and the band gap of the undoped PFu was found to be $2.7 \mathrm{eV}$. This study showed that doping generated mobile carriers with spins related to the increase of conductivity. McConnell analyzed the UV/Vis spectrum of $\mathrm{PFu}$ and found a broad absorption band with a maximum corresponding to a $\pi \rightarrow \pi^{*}$ transition.

Glenis et al. studied the UV/Vis absorption spectra of undoped and $\mathrm{CF}_{3} \mathrm{SO}_{3}{ }^{-}$-doped $\mathrm{PFu}$, and they found that the tran- 


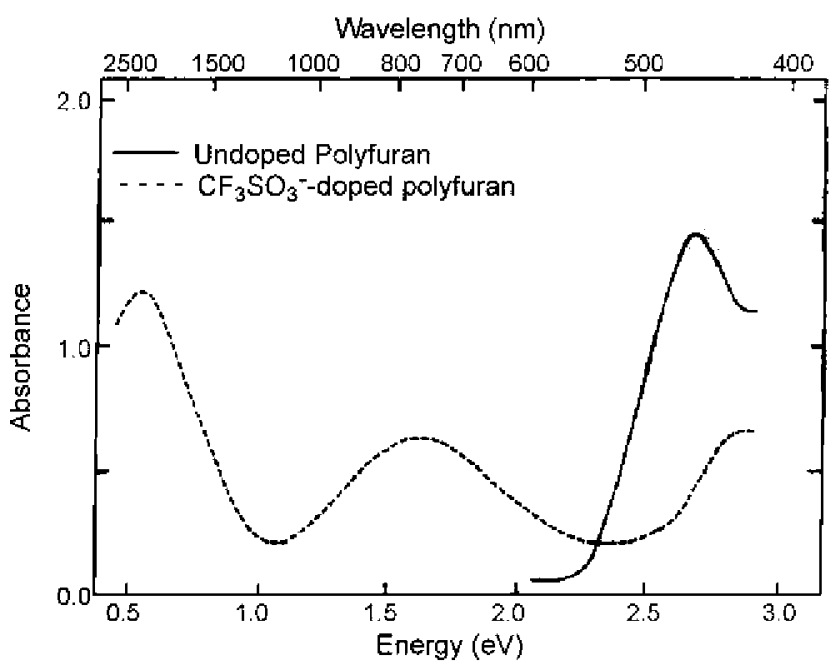

Fig. 7. UV-visible spectrum of a polyfuran-coated tin-doped indium oxide (ITO) electrode: (-) undoped; (---) $\mathrm{CF}_{3} \mathrm{SO}_{3}{ }^{-}$doped. (Figure reprinted with permission from ref. [17]. Copyright 1993. American Chemical Society).

sition from the undoped to the doped state was accompanied by a weakening and a blue shift of the absorption band in the visible region and by the appearance of two absorption bands in the near-IR region (see Fig. 7). These features were due to $\pi \rightarrow \pi^{*}$ and excitation transitions due to the high degree of conjugation of the aromatic polymer chains. The two subgap levels were attributed to bipolaronic transitions between band gap states, which arise as a consequence of electronic coupling with the polymer backbone.

UV/Vis spectrophotometry was also used to characterize the conducting composites made from PFu and P2IAn [35], P2ClAn [36], and P2FAn ; in all cases, the UV bands observed exhibited a shift to longer wavelengths, this shift reflecting enhanced conjugation in the polymer backbone in accordance with the increasing conductivity observed. In the case of $\mathrm{PFu} / \mathrm{P} 2 \mathrm{BrAn}$ composites I, two absorption maxima were found in the UV spectrum, as Glenis et al. had found

Galal showed for the first time the relationship between the wavelength of UV absorption and the oxidation potentials of oligomeric heterolenes containing furan and thiophene rings.

$\mathrm{PFu}$ polymer could be reversibly cycled according to UV data obtained by Tirkeş and Önal

\subsection{X-ray photoelectron spectroscopy, XPS}

The ability to distinguish between different oxidation states of atoms and their surroundings in a molecule is one of the major strengths of the XPS technique.

XPS results have shown that a counterion is invariably present in PFu samples. No positive charge is seen to be located on any given atom due to the absence of any energy shift for $\mathrm{C}$ and $\mathrm{O}$ and so this charge should be delocalized over the polymeric chain. del Valle also established that deconvolution of the $\mathrm{C} 1 \mathrm{~s}$ and $\mathrm{O} 1 \mathrm{~s}$ peaks showed the presence of $\mathrm{C}-\mathrm{C}, \mathrm{C}-\mathrm{O}-\mathrm{C}, \mathrm{C}-\mathrm{OH}$, and $\mathrm{COOH}$ bonds; decon-

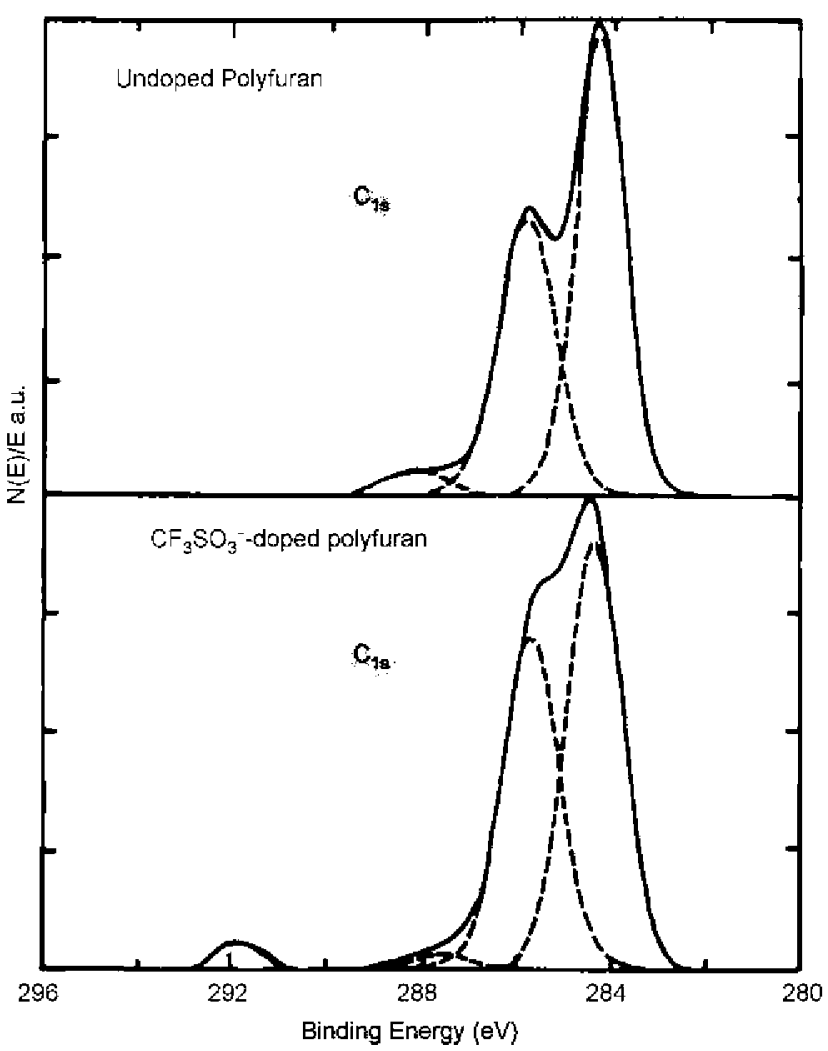

Fig. 8. C1s core level spectra of (a) undoped and (b) $\mathrm{CF}_{3} \mathrm{SO}_{3}$-doped polyfuran films. The features through the data correspond to the fitting with Gaussian functions. (Figure reprinted with permission from ref. [17]. Copyright 1993. American Chemical Society).

volution of both peaks confirmed that the furan rings were not destroyed during the electrochemical polymerization process.

Glenis et analyzed undoped and doped polyfuran with different anions (see Fig. 8). They established which type of carbon caused the spectra, the modification of the electronic structure of the polymer, and the transformations of the polymer chain from aromatic to quinoid-like structure during the doping process.

XPS analyses of Poly-1a and Poly-1b [68] suggested the presence of ketonic oxygen species, $\mathrm{C}=\mathrm{O}$, in addition to the furan oxygen, and an insignificant presence of the halogen. XPS data indicated that minor amounts of iodine had been incorporated into the polymers. These data were consistent with the formation of a polymer consisting of open- and closed-ring structures (see Scheme 6). XPS analyses for $\mathrm{C}, \mathrm{Cl}$, and Ti on a $\mathrm{PFu}-\mathrm{TiO}_{x}$ composite film revealed that the doping level was $29 \%$

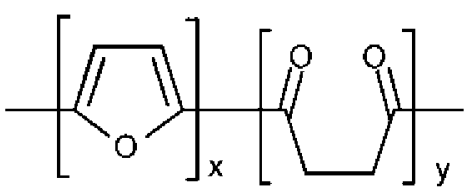

Scheme 6. Open and close ring structures found in Poly-1a and Poly1-b 


\subsection{Electron spin resonance spectroscopy, ESR}

ESR measurements have been performed in order to study the nature of polymer-chain defects (soliton, polaron, and bipolaron) and how these might relate to conduction mechanisms.

Oshawa observed that the ESR line width of PFu decreased upon doping from 10.8 (undoped) to 2.5 Gauss (doped), and that the signal type concomitantly changed from Gaussian to Lorentzian in shape. These observations confirmed that doping generated mobile carriers with spins related to the increase in conductivity.

ESR measurements on oxidized and reduced $\mathrm{PFu}$ were indicative of a low degree of conjugation, in contrast to measurements on PPy and PTh The $g$ value for PFu was found to be similar to that for other conjugated systems, indicating that the spin orbitals of the heteroatoms have an almost negligible effect.

The magnetic properties of undoped and $\mathrm{CF}_{3} \mathrm{SO}_{3}{ }^{-}$-doped $\mathrm{PFu}$ have been studied by magnetic susceptibility and ESR measurements by Glenis

The undoped polymer exhibited a Gaussian signal, which changed to a line shape intermediate between Gaussian and Lorentzian upon doping. A Gaussian ESR signal may be attributed to the presence of localized spins, whereas a Lorentzian nature of the signal indicates that some spins originate from mobile charges. The spin concentration decreased on going from undoped to doped samples, and the $g$ values for undoped and doped PFu indicated that the species responsible for the ESR signal originated principally from unpaired electrons in the conjugated $\pi$-electron system of the carbon backbone.

McConnell

found that the ESR spectrum of $\mathrm{PFu}$ exhibited a Gaussian signal, and that this ESR signal was most likely attributable to unpaired electrons in the conjugated $\pi$-system that might have come from defects in the polymer lattice.

Demirboğa and Önal used in situ ESR, at low temperature $(220-240 \mathrm{~K})$ under vacuum and at room temperature, in order to investigate the mechanism of electrochemical polymerization. The ESR spectrum of furan obtained during electrolysis indicated that radical cations formed after electron transfer immediately coupled with the elimination of $\mathrm{H}^{+}$. The resulting spectrum could be assigned to the radical cation of the dimer and/or to radicals stabilized in the polymer chain, indicating that polymerization in the case of furan occurred by an $\alpha, \beta$ mechanism. These results confirmed the PFu polymerization mechanism proposed in Scheme 1.

\subsection{NMR spectroscopy}

Armour

by taking into account NMR data, confirmed the structure suggested by IR data mentioned above.

Lamb used NMR data to confirm the presence of $\mathrm{OH}$ groups in the polymer and found that the 2-position was more highly substituted than the 3-position (see Scheme 2(c) and (d)).

A structural characterization of $\mathrm{PFu}$ by ${ }^{1} \mathrm{H}$ and ${ }^{13} \mathrm{C}$ NMR was conducted by Benvenuti

; both techniques led to the conclusion that the polymeric material consisted of a highly conjugated structure.

NMR spectra of doped PFu and co-polymers were studied by McConnell The PFu spectra showed about 6\% ring opening through the presence of aliphatic signals; the introduction of a small amount of pyrrole $(2 \%)$ or thiophene $(2 \%)$ into the PFu matrix helped to prevent ring opening and loss of aromaticity during the polymerization process (which was suppressed to $4 \%$ and $2 \%$, respectively).

\section{Morphological properties}

Polymer morphology greatly affects mechanical and electrical properties. For electronic applications, extremely smooth surfaces are required.

\subsection{Scanning electron microscopy, SEM}

Scanning electron microscopy has been one of the most widely used techniques in the study of the morphology of polymeric materials for analyzing their constituents and texture.

Tourillon and Garnier established that PFu possesses a regular and homogeneous morphology similar to that of PTh, while Glenis et al. commented only that polyfuran films doped with different anions showed a wide variation in their surface morphologies. Neither paper contained any experimental evidence.
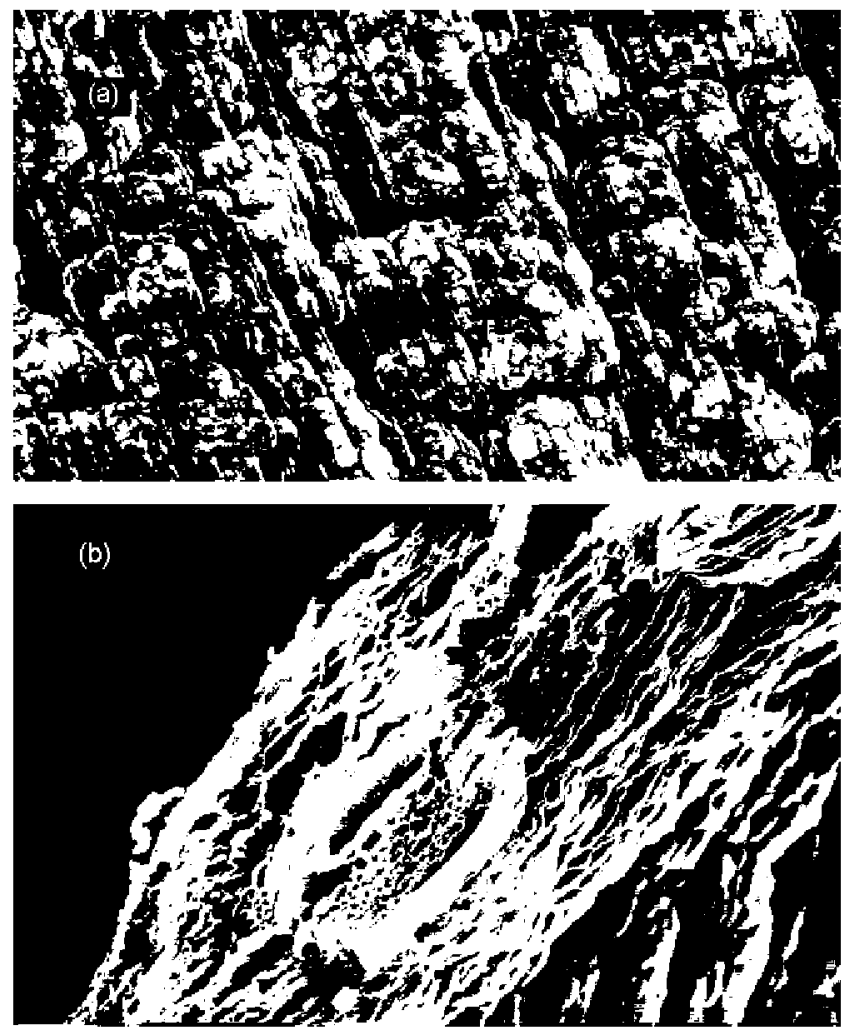

Fig. 9. (a) Scanning electron micrographs of (a) growth face and (b) cross section of $\mathrm{PFu} / \mathrm{ClO}_{4}$ films synthesized at $2.1 \mathrm{~V}$ and $[\mathrm{Fu}]=2\left[\mathrm{NaClO}_{4}\right]=0.4 \mathrm{M}$. (Figure reprinted with permission Inc.).
Copyright 2000 . John Wiley \& Sons, 


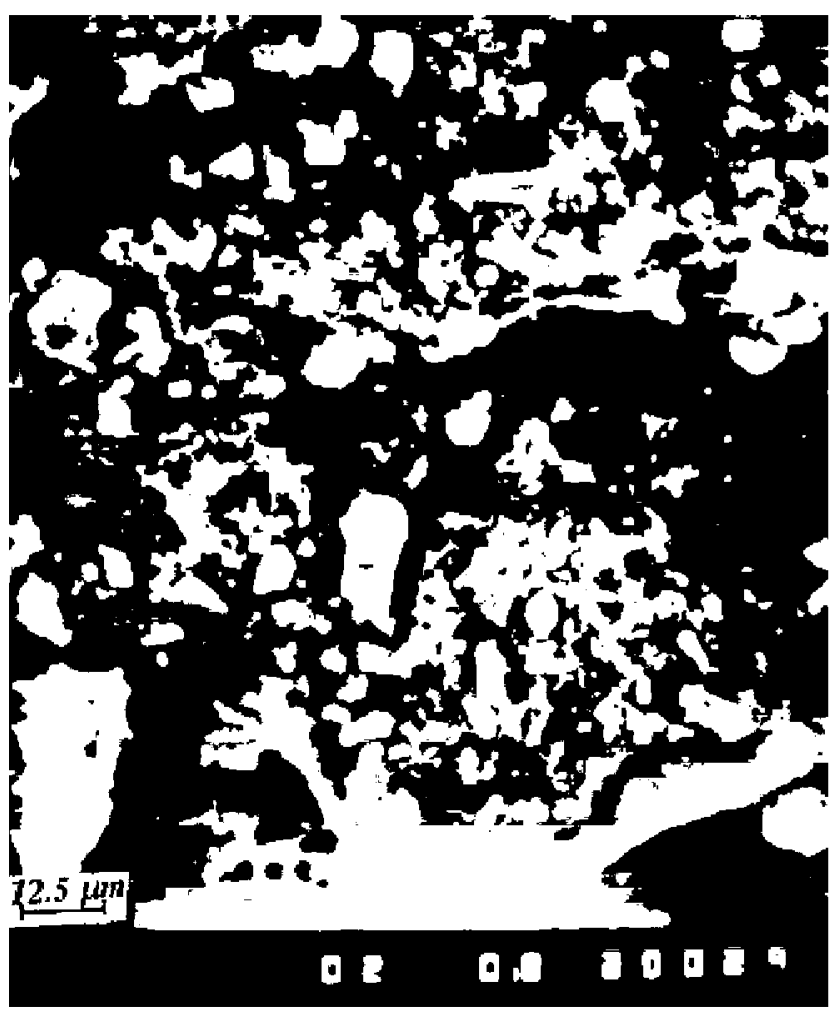

Fig. 10. SEM micrograph of PFu (magnification $800 \times$, bar $=12.5 \mu \mathrm{m}$ ). (Figure reprinted with permission Inc.).

Copyright 2003. John Wiley \& Sons,

The first clear evidence for an ordered and porous $\mathrm{PFu} / \mathrm{ClO} 4$ morphology was presented by Carrillo The solution side of the film was found to show an ordered nodular structure that was always oriented at $45^{\circ}$ with respect to the longitudinal axis of the Pt electrode (see Fig. 9(a)). The nodule area and the perimeter of the nodules were analyzed, from which it was established that the size diminished as the deposition potential was increased The electrode side of the film was found to be shiny and smooth, and more homogeneous than the other face. The cross-section displays a porous texture composed of interlinked layers of nodules, with some cavities between the layers caused by non-simultaneous nucleation and by an alternative growth mechanism parallel to the electrode surface (see Fig. 9(b)). It is interesting to point out that the ordered structure of these films was maintained up to $210^{\circ} \mathrm{C}$; at higher temperatures, decomposition of the films was visually apparent, although the order was maintained These results were confirmed by FTIR spectroscopy. A porous structure of polyfuran films was also found by Talu and Li et al.

The structure of $\mathrm{PFu}$ obtained using $\mathrm{SbCl}_{3}$ as oxidant changed to a nonporous and uniform one in the under layer and became granular and sponge-like on the upper surface (see Fig. 10)

This laminar porous structure could account for the low values of the PFu conductivity and its increase with the degree of hydration as Oshawa et al. established . Water molecules could be trapped within these structures, creating some connections among layers, thereby favoring ionic conductivity
As noted above, the nature of the electrolyte anion and monomer as well as the electrolyte concentration have a great influence on polymer growth. Likewise, when $\mathrm{PFu}$ was doped with tetrabutylammonium hexafluorophosphate $\left(\mathrm{Bu}_{4} \mathrm{NPF}_{6}\right)$, tetrabutylammonium tetrafluoroborate $\left(\mathrm{Bu}_{4} \mathrm{NBF}_{4}\right) \quad$ or tetraethylammonium perchlorate $\left(\mathrm{Et}_{4} \mathrm{NClO}_{4}\right)$, the surface morphology varied widely. Tirkes and Önal showed the influence of neat and mixed solvents on PFu morphology.

Both the electrode and solution sides of bipolymers or composites displayed different structures depending on the electrolytic medium employed and on the cover polymer. Depending on the electrolyte used, the resulting bipolymer could be a bilayer

or a co-polymer. Gök et al. studied the morphologies of composites of PFu and P2IAn , P2ClAn and P2FAn and concluded that all of them were compatible mixtures and that the guest polymer was homogeneously distributed throughout the host polymer. A composite composed of $\mathrm{P} 2 \mathrm{BrAn}\left[\left(\mathrm{NH}_{4}\right)_{2} \mathrm{~S}_{2} \mathrm{O}_{8}\right] / \mathrm{PFu}\left(\mathrm{SbCl}_{3}\right)$ exhibited both granular and uniform morphologies similar to those of the homopolymers

The SEM technique has also been used to study the morphologies of FeOCl crystals intercalated with $\mathrm{PFu}, \mathrm{PFu}-\mathrm{TiO}_{x}$ systems $\quad \mathrm{PFu}-\mathrm{Al}_{2} \mathrm{O}_{3}$ composite and $\mathrm{PFu} / \mathrm{AB}$ composite

\subsection{Transmission electron microscopy, TEM}

Transmission electron microscopy has not been so extensively applied to conducting polymers due to their lack of crystallinity. Only a few articles relating to $\mathrm{PFu}$ have appeared.

The existence of microdomains in ordered $\mathrm{PFu} / \mathrm{ClO}_{4}$ films has been established by means of TEM and electron diffraction analysis . Single crystals with lamellar structures (see Fig. 11) and randomly oriented crystals were detected in deep layers and at the growth surface, respectively

Selected area diffraction (SAD) of $\mathrm{PFu} / \mathrm{FeOCl}$ was used to demonstrate the crystallinity and structural integrity of the material. The ordering of the polyfuran chains in the lamellar space remained unknown as no diffraction spots corresponding to a supralattice were evident.

TEM images revealed the incorporation of $\mathrm{PFu}$ moieties between the MMT layers in PFu-PMMT and the formation of globular polymer-encapsulated acetylene black particles with an average diameter of around $100 \mathrm{~nm}$ in $\mathrm{PFu} / \mathrm{AB}$ composites

\subsection{X-ray diffraction analysis}

This technique has been used to demonstrate that doped $\mathrm{PFu}$ is formed on $\mathrm{SnO}_{2}$ as a semi-amorphous or poorly crystallized material, as well as to establish the intercalation of polyfuran in montmorillonite lamellae and in $\mathrm{FeOCl}$

The low crystallinity of doped polyfuran, which is lower than $10 \%$ (see Fig. 12), was enhanced when composites were formed with poly(2-halogenoaniline)s, which have a higher degree of crystallinity . The composites $\mathrm{PFu} / \mathrm{P} 2 \mathrm{XAn}$ and $\mathrm{P} 2 \mathrm{XAn} / \mathrm{PFu}$, 

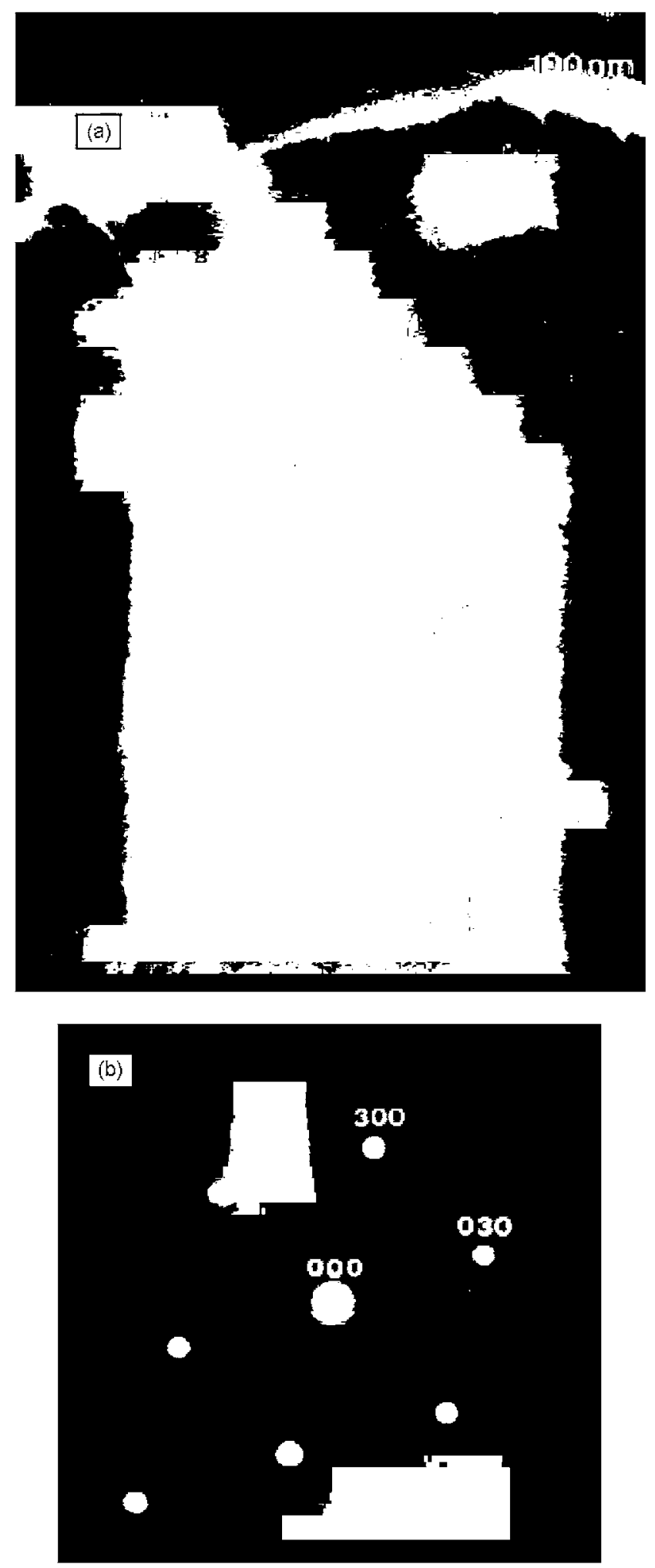

Fig. 11. (a) Transmission electron micrograph of a deep planar section of $\mathrm{PFu} / \mathrm{ClO}_{4}$ films. Evidence for lamellae can be identified (arrows). (b) Corresponding electron diffraction pattern (Figures reprinted with permission Copyright 1996. American Chemical Society).

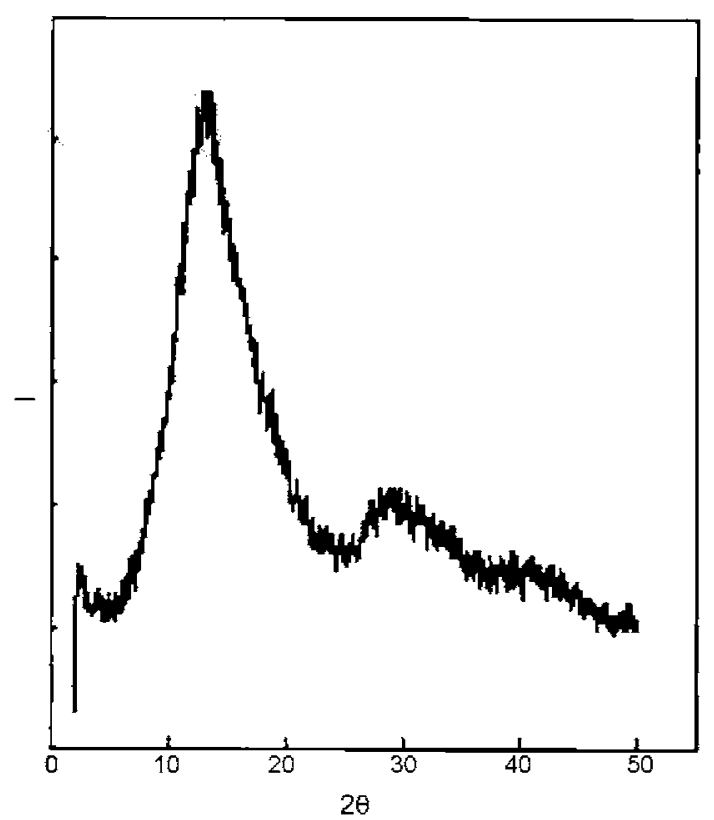

Fig. 12. X-ray diffraction pattern of PFu [41]. (Figure reprinted with permission from ref. [41]. Copyright 2005. Elsevier).

where $\mathrm{X}=\mathrm{Cl}, \mathrm{Br}$, or I, showed increased crystallinity when the $\mathrm{PFu}$ was synthesized first. The crystallinities of these composites were higher than those of their homopolymers. However, with $\mathrm{X}=\mathrm{F}$, the crystallinity of the PFu/P2FAn composite was lower than that of poly(2-fluoroaniline) but higher than that of the $\mathrm{P} 2 \mathrm{FAn} / \mathrm{PFu}$ composite.

\section{Thermal behavior}

By differential scanning calorimetry, DSC, different melting temperatures, $T_{\mathrm{m}}$, of polyfuran $\left(T_{\mathrm{m}}=103^{\circ} \mathrm{C}\right.$ and $200^{\circ} \mathrm{C}$

) have been published depending on the dopant anion. In neither case were any experimental data shown. Carrillo et al.

found neither a $T_{\mathrm{g}}$ nor a $T_{\mathrm{m}}$ for $\mathrm{PFu} / \mathrm{ClO}_{4}$; only an exothermic reaction was detected from $86^{\circ} \mathrm{C}$ to $190^{\circ} \mathrm{C}$ due to $\mathrm{NaClO}_{4}$ decomposition. From this temperature up to $250^{\circ} \mathrm{C}$, an exothermic reaction resulted from a morphological change.

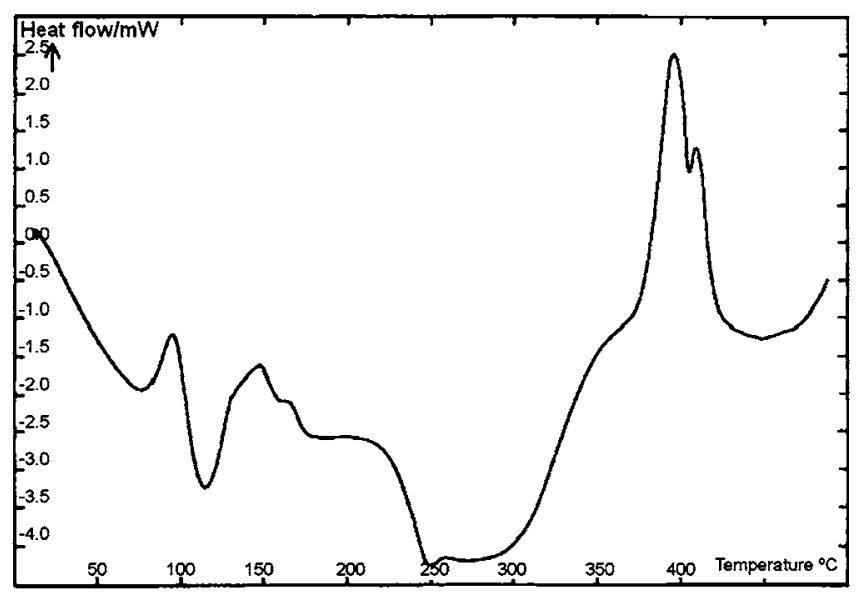

Fig. 13. DSC curve of PFu. (Figure reprinted with permission Copyright 2003. John Wiley \& Sons, Inc.). 
Table 7

The values of TGA analysis results of PFu conducting films: $T_{\mathrm{i}}=$ initial temperature; $T_{\mathrm{m}}=$ maximum decomposition temperature and $T_{\Gamma}=$ final temperature

\begin{tabular}{|c|c|c|c|}
\hline \multirow[t]{2}{*}{ Sample } & \multicolumn{3}{|c|}{$\begin{array}{l}\text { Decomposition temperature } \\
(\mathrm{CC})\end{array}$} \\
\hline & $T_{\mathrm{i}}$ & $T_{\max }$ & $T_{\Gamma}$ \\
\hline $\mathrm{PFu}-\mathrm{BuNBF}_{4}$ & \multicolumn{3}{|c|}{$300-400$} \\
\hline $\mathrm{PFu}-\mathrm{LiClO}_{4}$ & 215 & 260 & 300 \\
\hline $\mathrm{PFu} / \mathrm{Et}_{4} \mathrm{NBF}_{4}$ & 200 & 277 & 334 \\
\hline \multirow[t]{2}{*}{$\mathrm{PFu} / \mathrm{Bt}_{4} \mathrm{NPF}_{6}$} & 124 & 156 & 281 \\
\hline & 281 & 319 & 355 \\
\hline $\mathrm{PFu}$ & 114 & 181 & 273 \\
\hline \multirow[t]{2}{*}{ (Oxidant:SbCl$\left.)_{3}\right)$} & 273 & 341 & 409 \\
\hline & 518 & 541 & 568 \\
\hline \multirow[t]{2}{*}{$\mathrm{PFu}\left(\mathrm{FeCl}_{3}\right)^{\mathrm{a}}$} & 164 & 207 & 249 \\
\hline & 309 & 351 & 399 \\
\hline \multirow[t]{2}{*}{$\mathrm{PFu}\left(\mathrm{FeCl}_{3}\right)^{\mathrm{b}}$} & 168 & 198 & 231 \\
\hline & 231 & 348 & 677 \\
\hline $\mathrm{PFu}\left(\mathrm{FeCl}_{3}\right)$ & & & 351 \\
\hline $\mathrm{PFu}-\mathrm{BuNBF}_{4}$ & 185 & 253 & 312 \\
\hline $\mathrm{PFu}-\mathrm{G}$ & \multicolumn{3}{|l|}{$>180$} \\
\hline $\mathrm{PFu}-\mathrm{G}^{\prime}$ & \multirow{2}{*}{\multicolumn{3}{|c|}{$>180$}} \\
\hline (Catalyst: $\mathrm{CH}_{3} \mathrm{C}-\mathrm{COOH}$ ) & & & \\
\hline \multicolumn{3}{|l|}{$\mathrm{PFu} . \mathrm{Cl}\left(\mathrm{FeCl}_{3}\right.$ doped with $\left.\mathrm{I}_{2}\right)$} & 500 \\
\hline $\mathrm{PFu}$ & 95 & 164 & 210 \\
\hline \multirow[t]{2}{*}{$\mathrm{Bu}_{4} \mathrm{NBF}_{4}$} & 210 & & 300 \\
\hline & 300 & & 500 \\
\hline
\end{tabular}

a $\mathrm{PFu}$ synthesized in $\mathrm{CH}_{3} \mathrm{CN}$ medium.

${ }^{b} \mathrm{PFu}$ synthesized in $\mathrm{CHCl}_{3}$ medium.

For chemically synthesized $\mathrm{PFu}$, three endothermic reactions $\left(79^{\circ} \mathrm{C}, 115^{\circ} \mathrm{C}\right.$, and $250^{\circ} \mathrm{C}$ ) were found by DSC (see Fig. 13). The first two peaks indicated the loss of units with low molecular weight such as monomers or solvents present in the $\mathrm{PFu}$. The peak at $250^{\circ} \mathrm{C}$ indicated the loss of the dopant anions. Moreover, a glass transition was observed at $171^{\circ} \mathrm{C}$.

$\mathrm{PFu} / \mathrm{P} 2 \mathrm{ClAn}, \mathrm{P} 2 \mathrm{ClAn} / \mathrm{PFu}$, and PFu:P2ClAn (1:1) mechanical mixture composites were analyzed, and similar curves to that of the homopolymer were found _ _ . These composites also exhibited three endothermic peaks, but no $T_{\mathrm{g}}$ was detected.

Thermogravimetric analysis of different polyfuran samples revealed a degree of stability up to temperatures close to $100^{\circ} \mathrm{C}$ (Table 7). For $\mathrm{PFu}$ chemically synthesized with trichloroacetic acid [62], however, the decomposition temperature was higher than $180^{\circ} \mathrm{C}$. Tourillon and Garnier stated that $\mathrm{PFu}$ was resistant to temperatures of $300-400^{\circ} \mathrm{C}$, but no evidence was provided.

The temperature at which $\mathrm{PFu}$ degradation occurred was $500^{\circ} \mathrm{C}$

(see Fig. 14). Below this temperature, a progressive loss of weight was observed. Decomposition took place in three steps (see Table 7). The initial mass loss in the range $50-120^{\circ} \mathrm{C}$ could be mainly attributed to the release of moisture, solvent, and dopant molecules from the polymer surface. In the second decomposition step, polymerchain structures decomposed after the elimination of the dopants. The final step corresponded to the degradation of the polymer. it was reported that $\mathrm{PFu}$ samples doped with $\mathrm{FeCl}_{3}$

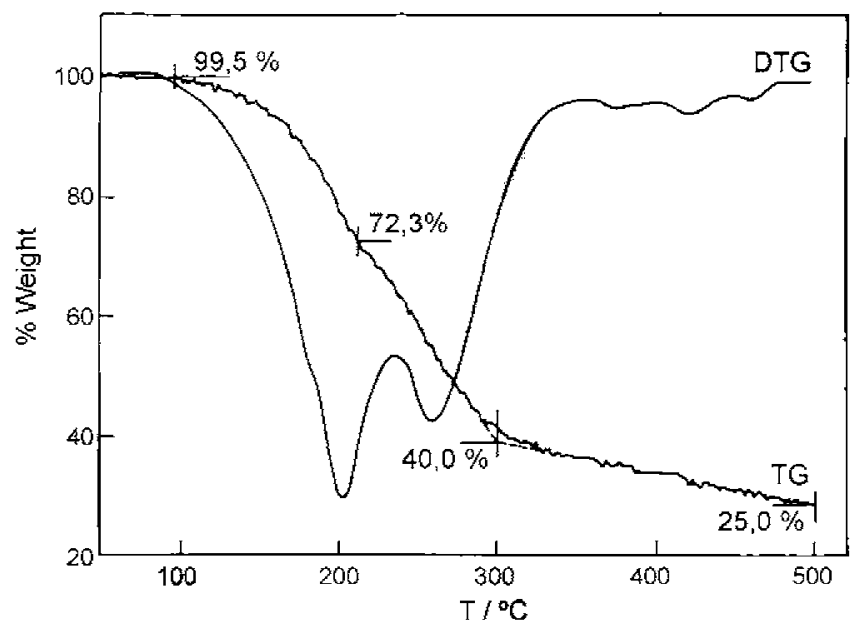

Fig. 14. TG and DTG curves of $\mathrm{PFu} / \mathrm{ClO}_{4}$ films from 30 to $500^{\circ} \mathrm{C}$. (Figure reprinted with permission from ref. [82]. Copyright 1999. Springer Science and Business Media).

also decomposed in two steps. In the same way, depending on the supporting electrolyte, Kabasakoloğlu established that $\mathrm{PFu}$ decomposed in one or two stages when it was obtained with $\mathrm{Et}_{4} \mathrm{NBF}_{4}$ or $\mathrm{Bu}_{4} \mathrm{NPF}_{6}$, respectively.

The thermal stability of $\mathrm{PFu}$ is increased in its composites with poly(halogenoaniline) (see Fig. 15). The thermal properties of these composites were found to be intermediate between those of the pure polymers, with different behavior being observed depending on the order of synthesis of the polymer and the halogenoaniline used (see Table 8). Thus, the P2FAn/PFu, PFu/P2ClAn, and $\mathrm{PFu} / \mathrm{P} 2 \mathrm{IAn}$ composite systems were found to be more thermally stable than the PFu/P2FAn, $\mathrm{P} 2 \mathrm{ClAn} / \mathrm{PFu}$, and P2IAn/PFu systems. $\mathrm{P} 2 \mathrm{BrAn}\left(\mathrm{FeCl}_{3}\right) / \mathrm{PFu}\left(\mathrm{SbCl}_{3}\right)$ and $\mathrm{P} 2 \mathrm{BrAn}\left[\left(\mathrm{NH}_{4}\right)_{2} \mathrm{~S}_{2} \mathrm{O}_{8}\right] / \mathrm{PFu}\left(\mathrm{SbCl}_{3}\right)$ composites decomposed in two steps and one step, respectively and their thermal stabilities were intermediate between those of pure $\mathrm{PFu}$ and $\mathrm{P} 2 \mathrm{BrAn}$, indicating enhancement of the thermogravimetric stability of PFu.

The thermal stability of $\mathrm{PFu}$ was also enhanced when composites were formed with highly stable $\mathrm{Al}_{2} \mathrm{O}_{3} \quad$ MMT or acetylene black

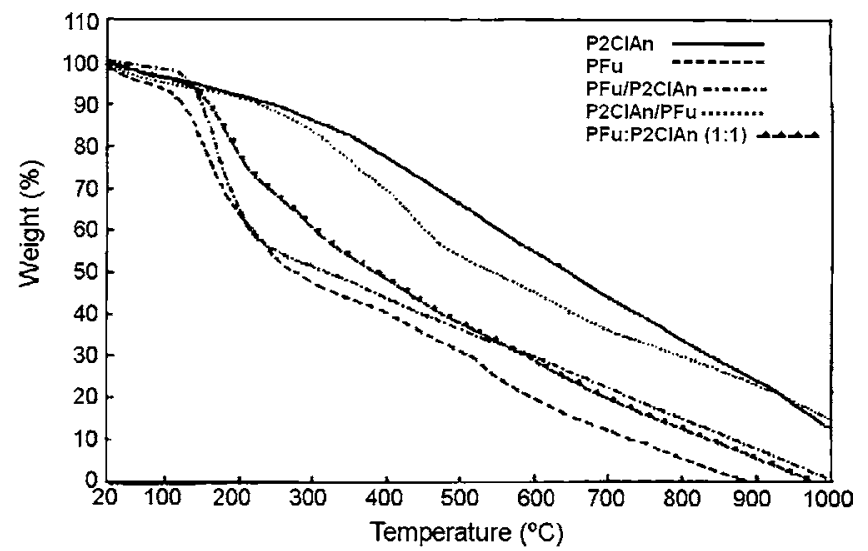

Fig. 15. TGA thermograms of polymers. (Figure reprinted with permission from Copyright 2003. John Wiley \& Sons, Inc.). 
Table 8

The values of TGA analysis results of $\mathrm{PFu}$ composites conducting films: $T_{\mathrm{i}}=$ initial temperature; $T_{\mathrm{m}}=$ maximum decomposition temperature; and $T_{\mathrm{f}}=$ final temperature

\begin{tabular}{llll}
\hline Sample & \multicolumn{3}{c}{$\begin{array}{l}\text { Decomposition } \\
\text { temperature }\left({ }^{\circ} \mathrm{C}\right)\end{array}$} \\
\cline { 2 - 4 } & $T_{\mathrm{i}}$ & $T_{\max }$ & $T_{\mathrm{f}}$ \\
\hline PFu/P2IAn & 225 & 326 & 400 \\
P2IAn/PFu & 172 & 278 & 359 \\
PFu:P2IAn $(1: 1$ mechanical & 150 & 260 & 370 \\
mixture $)$ & & & \\
$\mathrm{PFu} / \mathrm{P} 2 \mathrm{FCl}$ & 255 & 364 & 464 \\
$\mathrm{P} 2 \mathrm{ClAn} / \mathrm{PFu}$ & 136 & 173 & 227 \\
$\mathrm{PFu}: \mathrm{P} 2 \mathrm{ClAn}$ & 148 & 209 & 318 \\
$\mathrm{PFu} / \mathrm{P} 2 \mathrm{FAn}(54 \%)$ & 165 & 200 & 253 \\
& 326 & 351 & 383 \\
$\mathrm{P} 2 \mathrm{FAn} / \mathrm{PFu}(77 \%)$ & 213 & 387 & 544 \\
$\mathrm{PFu}: \mathrm{P} 2 \mathrm{FAn}(1: 1$ mechanical & 217 & 226 & 239 \\
mixture $)$ & & & \\
& 307 & 341 & 353 \\
$\mathrm{P} 2 \mathrm{BrAn}\left(\mathrm{FeCl}{ }_{3}\right) / \mathrm{PFu}\left(\mathrm{SbCl}_{3}\right)$ & 196 & 216 & 240 \\
$\mathrm{P} 2 \mathrm{BrAn}\left[\left(\mathrm{NH}_{4}\right)_{2} \mathrm{~S}_{2} \mathrm{O}_{8}\right] / \mathrm{PFu}\left(\mathrm{SbCl}_{3}\right)$ & 310 & 345 & 383 \\
& 144 & 256 & 417 \\
$\mathrm{PFu}-\mathrm{Al}{ }_{2} \mathrm{O}_{3}$ & 352 & & \\
$\mathrm{PFu}-\mathrm{MMT}$ & 408 & & \\
\hline
\end{tabular}

Co-polymers of furan and 3-methylthiophene began to decompose at the same initial temperature as $\mathrm{PFu}$, but as the temperature was increased the behavior of the decomposition was similar to that seen for poly(3-methylthiophene) (see Table 9)

Table 9

The values of TGA analysis results of $\mathrm{PFu}$ co-polymers and bipolymers conducting films: $T_{\mathrm{i}}=$ initial temperature; $T_{\mathrm{m}}=$ maximum decomposition temperature; and $T_{\mathrm{f}}=$ final temperature

\begin{tabular}{|c|c|c|c|c|}
\hline \multirow[t]{2}{*}{ References } & \multirow[t]{2}{*}{ Sample } & \multicolumn{3}{|c|}{$\begin{array}{l}\text { Decomposition } \\
\text { temperature }\left({ }^{\circ} \mathrm{C}\right)\end{array}$} \\
\hline & & $T_{\mathrm{i}}$ & $T_{\max }$ & $T_{\mathrm{f}}$ \\
\hline \multicolumn{5}{|c|}{ Co-polymers } \\
\hline & $\mathrm{Fu}$ and $3 \mathrm{MTh}$ & 190 & 330 & 453 \\
\hline \multicolumn{5}{|l|}{ Bipolymer } \\
\hline & $\mathrm{PFu} / \mathrm{PTh}$ & 230 & 291 & 355 \\
\hline & & 480 & 513 & 541 \\
\hline & $\mathrm{PTh} / \mathrm{PFu}$ & 152 & 162 & 218 \\
\hline & & 369 & 380 & 391 \\
\hline & $\begin{array}{l}\text { PFu:PTh ( } 1: 1 \text { mechanical } \\
\text { mixture) }\end{array}$ & 218 & 254 & 295 \\
\hline & & 659 & 686 & 713 \\
\hline & $\mathrm{PFu} / \mathrm{PTh} / \mathrm{Et}_{4} \mathrm{NF}_{4} \mathrm{~B}$ & 183 & 231 & 296 \\
\hline & $\mathrm{PTh} / \mathrm{PFu} / \mathrm{Et}_{4} \mathrm{NF}_{4} \mathrm{~B}$ & 466 & 568 & 584 \\
\hline & $\begin{array}{l}\mathrm{PFu} / \mathrm{PTh} / \mathrm{Et}_{4} \mathrm{NF}_{4} \mathrm{~B} \\
\text { (1:1 mechanical mixture) }\end{array}$ & 198 & 245 & 272 \\
\hline & $\mathrm{PFu} / \mathrm{PTh} / \mathrm{Bt}_{4} \mathrm{NF}_{6} \mathrm{P}$ & 115 & 127 & 212 \\
\hline & & 530 & 636 & 693 \\
\hline & $\mathrm{PTh} / \mathrm{PFu} / \mathrm{Bt}_{4} \mathrm{NF}_{6} \mathrm{P}$ & 214 & 265 & 314 \\
\hline & & 314 & 358 & 419 \\
\hline & $\mathrm{PFu}: \mathrm{PTh} / \mathrm{Bt}_{4} \mathrm{NF}_{6} \mathrm{P}$ & 319 & 541 & 722 \\
\hline & (1:1 mechanical mixture) & 200 & 256 & 318 \\
\hline & & 314 & 382 & 457 \\
\hline & & 425 & 568 & 735 \\
\hline
\end{tabular}

This might be attributed to the relatively short chains of furan units and relatively long chains of 3-methylthiophene units in the co-polymer.

Other authors have used TGA to probe whether the polymerization of different polymers led to bipolymers or co-polymers. Kabasakoloğlu demonstrated that PFu/PTh bipolymers were of a bilayer type whereas PTh/PFu bipolymers had a co-polymer structure. Talu revealed that there was no chemical bonding between the bipolymers $\mathrm{PFu} / \mathrm{PTh}$ or $\mathrm{PTh} / \mathrm{PFu}$ and that they had a bilayer structure.

\section{Magnetic properties}

Magnetic measurements on conducting polymers establish a relationship between the charge carriers and the conductivity.

In furan intercalated in iron oxychloride, $\mathrm{PFu} / \mathrm{FeOCl}$, the magnetic properties of the reduced FeOCl layers dominate, this being a paramagnetic material

Glenis established that the magnetic susceptibility of $\mathrm{PFu} / \mathrm{CF}_{3} \mathrm{SO}_{3}$ was $5.3 \times 10^{-3} \mathrm{emu} / \mathrm{mol}$ per furan ring. Analysis of the influence of temperature on the magnetic susceptibility data showed the presence of free radicals on the polymer backbone.

Magnetic susceptibility data for PFu and its bipolymers with PTh showed that the polymers were diamagnetic in nature and that the conductivity mechanism was of the bipolaron type Similar results were found using $\mathrm{LiClO}_{4}$ as the supporting electrolyte Gök et al. studied the magnetic susceptibilities of different polyfuran composites with poly(2-halogenoaniline)s Some of these systems (PFu/P2FAn, 1:1 PFu:P2ClAn mechanical mixture, and 1:1 PFu:P2IAn mechanical mixture) displayed paramagnetic properties, while the others $(\mathrm{PFu}$, P2FAn/PFu, PFu/P2ClAn, PFu/P2IAn, and 1:1 PFu:P2FAn mechanical mixture) displayed diamagnetic properties. Nevertheless, in $\mathrm{P} 2 \mathrm{ClAn} / \mathrm{PFu}$ and $\mathrm{P} 2 \mathrm{IAn} / \mathrm{PFu}$, increasing amounts of $\mathrm{PFu}$ shifted the magnetic susceptibility to more positive values by increasing the number of polaron groups in the structure.

Similarly, $\quad \mathrm{PFu}\left(\mathrm{FeCl}_{3}\right)$ and $\mathrm{P} 2 \mathrm{BrAn}\left[\left(\mathrm{NH}_{4}\right)_{2} \mathrm{~S}_{2} \mathrm{O}_{8}\right] /$ $\mathrm{PFu}\left(\mathrm{SbCl}_{3}\right)$ displayed diamagnetic properties However, paramagnetic properties, that is, a polaron structure, have been found in $\mathrm{PFu}\left(\mathrm{SbCl}_{3}\right)$ and its composite $\mathrm{P} 2 \mathrm{BrAn}\left(\mathrm{FeCl}_{3}\right) / \mathrm{PFu}\left(\mathrm{SbCl}_{3}\right)$

\section{Theoretical calculations on PFu}

Various theoretical investigations and molecular modeling studies of conjugated organic molecules and polymers have been carried out in order to determine the values of the parameters related to conduction properties, such as band gap, ionization potential (IP), electron affinity (EA), torsion angle, coplanarity, etc. It is known that band gap values are related to the conduction properties of the undoped systems, whereas ionization potentials and electron affinities determine the ability of the system to form conducting polymers and therefore to have technological applications.

The most important electronic properties of PFu are summarized in Table 10. 
Table 10

Calculated electronic properties for $\mathrm{PFu}$

\begin{tabular}{|c|c|c|c|c|}
\hline $\begin{array}{l}\text { Valence-band } \\
\text { width }(\mathrm{eV})\end{array}$ & $\begin{array}{l}\text { Conduction-band } \\
\text { width }(\mathrm{eV})\end{array}$ & $\begin{array}{l}\text { Ionization Potential (top } \\
\text { of valence band) (eV) }\end{array}$ & $\begin{array}{l}\text { Electron affinity (value of } \\
\text { bottom of cond. band) }(\mathrm{eV})\end{array}$ & Band gap $(\mathrm{eV})$ \\
\hline 7.52 & 5.39 & 7.63 & -0.40 & $8.03(2.70)$ \\
\hline- & - & - & - & $\begin{array}{l}1.937(\mathrm{~A})^{\mathrm{b}} \\
0.595(\mathrm{Q})\end{array}$ \\
\hline- & - & 7.86 & 1.21 & 6.65 \\
\hline- & - & 6.70 & - & 6.5 \\
\hline- & - & 7.86 & 1.21 & 6.65 \\
\hline- & - & - & - & $\begin{array}{r}3.07(\mathrm{~A}) \\
-0.78(\mathrm{Q})\end{array}$ \\
\hline $1.94\left(\mathrm{Y}_{1}\right)$ & $0.82\left(\mathrm{Y}_{1}\right)$ & $7.53\left(\mathrm{Y}_{1}\right)$ & $1.74\left(\mathrm{Y}_{1}\right)$ & $5.79\left(\mathrm{Y}_{1}\right)$ \\
\hline $1.91\left(\mathrm{Y}_{2}\right)$ & $0.79\left(\mathrm{Y}_{2}\right)$ & $8.30\left(\mathrm{Y}_{2}\right)$ & $2.46\left(\mathrm{Y}_{2}\right)$ & $5.84\left(\mathrm{Y}_{2}\right)$ \\
\hline $1.82\left(\mathrm{Y}_{3}\right)$ & $0.62\left(\mathrm{Y}_{3}\right)$ & $7.81\left(\mathrm{Y}_{3}\right)$ & $2.10\left(\mathrm{Y}_{3}\right)$ & $5.71\left(\mathrm{Y}_{3}\right)$ \\
\hline $1.91\left(\mathrm{Y}_{4}\right)$ & $0.42\left(\mathrm{Y}_{4}\right)$ & $8.42\left(\mathrm{Y}_{4}\right)$ & $2.83\left(\mathrm{Y}_{4}\right)$ & $5.59\left(\mathrm{Y}_{4}\right)$ \\
\hline- & 1.0 & - & - & 3.3 \\
\hline 2.477 & 1.237 & 10.257 & -0.859 & 11.158 \\
\hline 4.205 & 4.215 & 9.740 & 0.891 & $8.849(2.7)$ \\
\hline 4.454 & 3.330 & 7.883 & -0.490 & $8.373(2.7)$ \\
\hline- & - & - & - & 7.03 \\
\hline- & - & - & - & 2.16 \\
\hline 3.77 & 3.48 & 5.31 & 2.63 & $2.67(2.35)$ \\
\hline 3.23 & 2.79 & - & - & 1.34 \\
\hline
\end{tabular}

a Values in parentheses indicate the experimental band gap.

b (A) and (Q) are aromatic and quinoid forms, respectively.

c Calculated electronic properties for completely linked $(\alpha-\beta) \mathrm{PFu}$.

Surprisingly, theoretical data indicate that $\alpha, \beta$-linked $\mathrm{PFu}$ has the largest band gap, the highest ionization potential, and the lowest electron affinity . In the same way, the band gap of the aromatic form is higher than that of the quinoid form

Semi-empirical calculation methods have been applied to $\mathrm{PFu}$ polymers to calculate their geometries and band structures, to examine the heteroatom effect on the $\pi$-band structure, to compare the ionization potentials (IP) and electron affinities (EA) with those of PPy and PTh, to study the dependence of structural, electronic, and dynamic properties as a function of conjugation length , and to compute their equilibrium geometries According to the concepts of the effective conjugation coordinate (ECC) model, Hernandez found that for short oligomers, $\pi$-electron delocalization is confined and the values of the corresponding force constant are higher. On going from dimer $(\mathrm{Fu})_{2}$ to polymer, the dispersion $v_{1}$ /force constant for the totally symmetric mode changes, showing that this mode is chain dependent. Using this method, the authors were able to interpret the vibrational spectra of PFu. By this formalism, López Navarrete et al. tried to interpret the photoinduced IR spectrum of $\mathrm{PFu}$. These methods were applied to optimize the geometrical parameters of $\mathrm{PFu}$ in the aromatic and quinoid forms and in the case of $\mathrm{PFu}$ bridged by electron-acceptor groups see Table 10 . The main idea behind donor-acceptor polymers is that a regular alternation of conjugated donor-acceptorlike moieties in a conjugated chain will induce a low band gap.
Ivanov deduced that the heteroatom perturbed the $\pi$-electronic structure of the carbons and that the system was constrained to remain planar. A theoretical analysis of polarons and bipolarons in neutral and charged poly(Fu-Th-Fu) oligomers with syn and anti chains was carried out by Doretto and Laks from which it was found that both configurations have almost the same equilibrium geometry. The UV/Vis absorption spectra were simulated and a coherent interpretation of the experimental spectra of doped PFu was obtained. Six different semi-empirical methods were applied to compare the band gap energies of PFu oligomers $(n=1-4)$ and a set of 60 structurally well-defined heterocyclic oligomers of $\mathrm{PFu}$ with PTh and its derivatives Hong found two minima separated by a rotational energy barrier of $2.44 \mathrm{kcal} / \mathrm{mol}$ per monomer unit in the conformational potential energy curve for $\mathrm{PFu}$.

Bakhshi

studied the effect of $\alpha, \beta$-linkages on the electronic structure and conduction properties of PFu and its co-polymers with polypyrrole and polythiophene. Theoretical structural parameters for PFu are listed in Table 10.

Similarly, ab initio Hartree-Fock crystal orbital calculations have been employed to determine the density of states for $\mathrm{PPy} / \mathrm{PFu}$ and $\mathrm{PTh} / \mathrm{PFu}$ co-polymers On the basis of the results, it was predicted that the weakest candidate for the generation of conductive materials through oxidative doping was PFu.

Villar determined the energy band structure of the infinite periodic systems by ab initio methods (see Fig. 16). The band gap value extrapolated using a linear regression for 


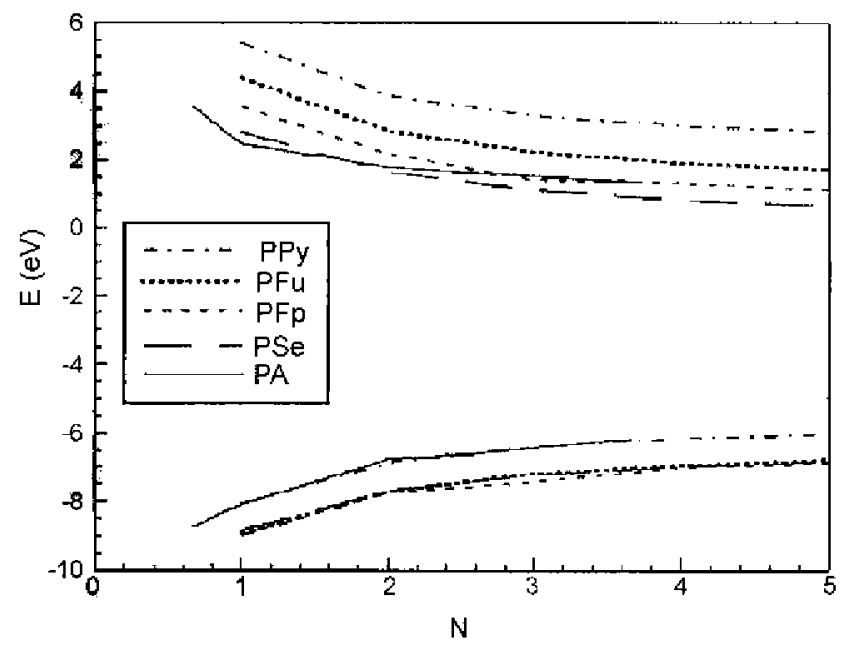

Fig. 16. Frontier orbitals (HOMO and LUMNO) for PPy, $\mathrm{pFu}$ and polythiophene (PTp), polyselonphene(PSe) and all-trans polyacetylene (PA) (Figure reprinted with permission from ref. [105]. Copyright 1993. Elsevier).

three to five units in the case of PFu is included in Table 10. Electron correlation was not included in the $\mathrm{PFu}$ calculations.

$\mathrm{Ab}$ initio calculations at the HF and MP2 levels have also been carried out for bi- and trifuran oligomers Internal rotation barriers, optimized geometries, orbital energies, and a vibrational spectrum calculated with the $6-31 \mathrm{G}$ basis set were reported. The discussion was focused on the influence of electron correlation on the computed properties.

The unperturbed energy band structure of $\mathrm{PFu}$ and the effect of electron correlation on the polarizabilities have been calculated by Otto using the second-order Møller-Plesset perturbation theory for polymers. The convergence of different types of polarizabilities at the coupled perturbed Hartree-Fock crystal orbital (CO) level has been studied, as reported in ref.

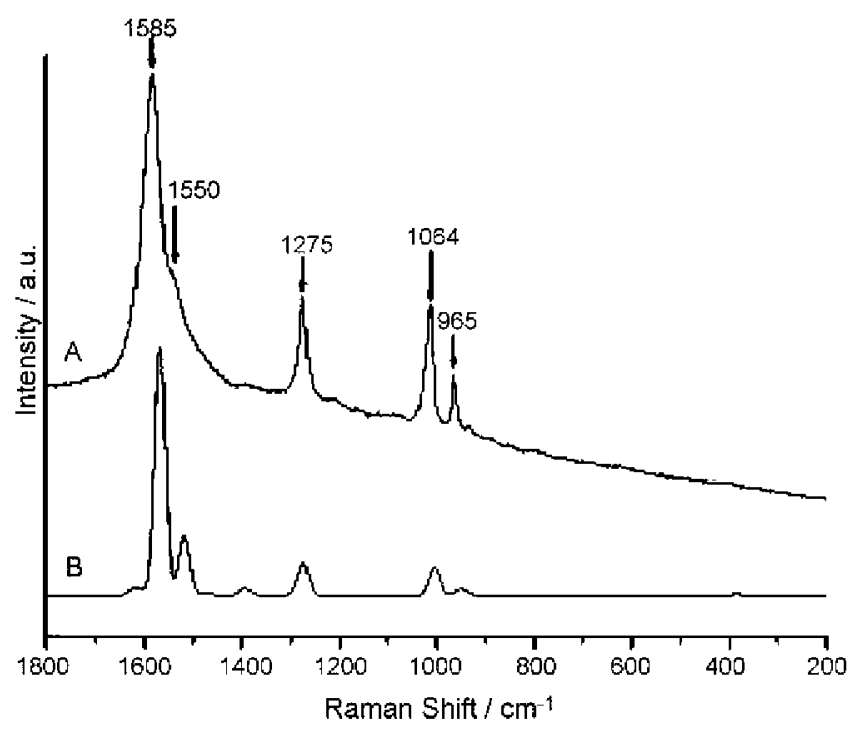

Fig. 17. Observed Raman spectrum of neutral PFu (spectrum A) and calculated Raman spectrum of neutral $\mathrm{Fu}_{6}$ at the BL 3 YP/6-31G* level (spectrum B). (Figure reprinted with permission Copyright 2004. American Chemical Society).

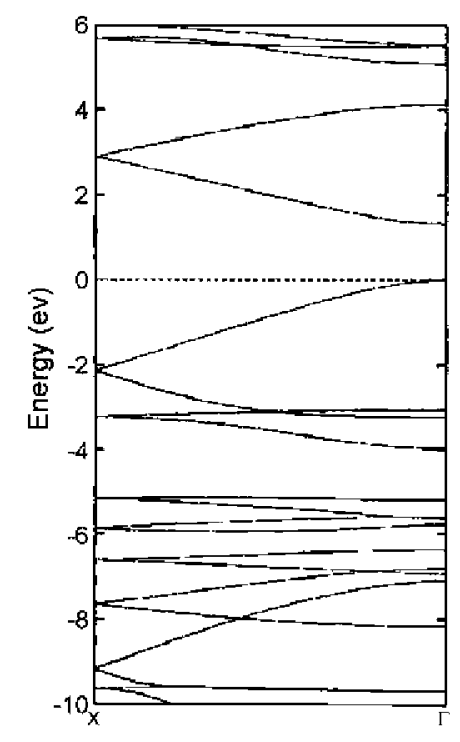

Fig. 18. (a) Calculated band structures of polyfuran plotted relative to the calculated valence band maxima. (Figure reprinted with permission from ref. [113]. Copyright 2003. American Physical Society).

Theoretical Raman spectra of PFu in the doped and de-doped states were calculated by Liu using the Gaussian 98 program at the DFT/B3LYP/6-31G* level. The results were in good agreement with the recorded Raman spectra (see Fig. 17).

The application of DFT at the B $3 \mathrm{LYP} / 6-31 \mathrm{G}(\mathrm{d})$ level to the extrapolation of oligomer HOMO-LUMO gaps using a secondorder polynomial equation or, alternatively, the application of PBC/B3LYP/6-31G(d), is a very good method for reliably predicting (to within a couple of tenths of electronvolts) the band gaps of conjugated polymers

Bantaculo studied furan dimer in the gas phase by $a b$ initio and density functional theory (DFT) calculations and estimated the heat of formation of $\mathrm{PFu}$. Their data were in good agreement with those obtained experimentally. DFT has also been applied to optimize the geometries of monomers through analysis of the hexamers of several monomers, including furan Theoretical and experimental data are included in Table 10. The authors concluded that the electronic properties of ordered infinite chains of $\mathrm{PFu}$ were not inferior to those of PTh and PPy.

Band gaps and effective conjugation lengths of furan polymers have been estimated by extrapolating vertical excitation energies of trimers through pentamers to infinite chain length

The excitation energies varied from 6.31 to $1.69 \mathrm{eV}$, the experimental value being $2.35 \mathrm{eV}$. These authors applied timedependent density functional theory with the B3LYP functional.

Hutchison studied the limitations of the oligomer extrapolation approximation and the effects of heteroatoms. They applied density functional methods and deduced that PFu has a lower calculated band gap (see Fig. 18) than PPy and a large conduction bandwidth, as well as a similarly broad band dispersion, which would imply that the material might potentially be doped; see Table 10 .

Montejo established the existence of a hydrogen bond between two adjacent furan rings, through which some 


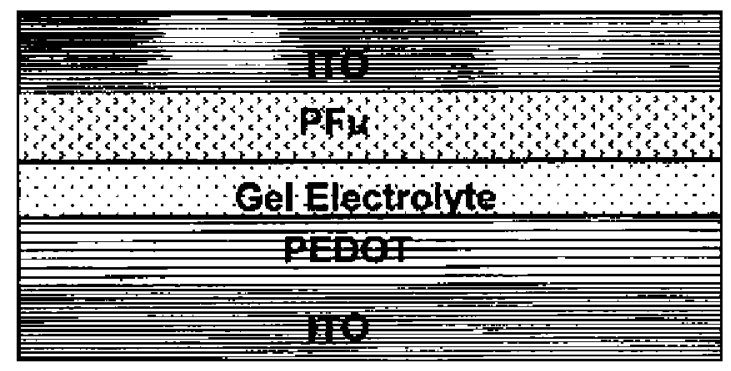

Scheme 7. Construction of device based on PFu. (Figure reprinted with permission

Copyright 2006. John Wiley \& Sons, Inc.).

electronic charge may be transferred along the $\pi$-electron system. This result provided a model of the interaction between end groups of neighboring $\mathrm{PFu}$ chains.

\section{Applications}

The nature of the oxidation and reduction processes occurring in conducting polymers is key for their technological applications, as is the kinetics of these processes.

The potential applications of polyfuran conducting polymers were first pointed out by Oshawa

They proposed that $\mathrm{PFu}$ might be used as a humidity sensor by virtue of its conductivity changing reversibly with humidity. The use of chemically synthesized $\mathrm{PFu}$ in optoelectronic devices was established by Yoshino et al. Tirkeş and Önal investigated the use of dual-type electrochromic devices made up of $\mathrm{PFu}$ and poly(3,4-ethylenedioxythiophene) in a sandwich configuration (see Scheme 7), which exhibited color changes between yellowish-green and blue. Ogawa et al. prepared a polyfuran-titanium oxide mixed system that could be used to fix atmospheric nitrogen under mild conditions.

Meanwhile, a lot of patents have been filed in relation to the possible applications of PFu conducting polymers. Its use in chromatography as a coating for the stationary phase material was proposed by Wallace while Ito et al. proposed its use as a low-frequency nonlinear electric material. However, the electrochemical behavior of $\mathrm{PFu}$ is responsible for its principal applications, such as in solid electrolytic capacitors rechargeable secondary batteries

catalysts conducting polymer-grafted carbon materials for fuel cell applications and electrically conducting lubricating greases for electric motors and bearing assemblies Photovoltaic cells and photoelectrochemical cells for the conversion of solar energy to electricity are $\mathrm{PFu}-\mathrm{containing}$ devices based on the principles of photoelectrochemistry. PFu has also been proposed as a component in a new plating method

Another area of application of conducting polymers is in shieldings against discharges and radiation, in antistatic wrapping materials for electronic components

as an antistatic layer support for silver halide photographic materials and in antistatic coatings Moreover, polyfuran polymers can also absorb electromagnetic energy at low frequencies, as a result of which they may be used as electromagnetic interference shields shielding against microwaves The electrical properties of $\mathrm{PFu}$ allow its application in field-effect transistors

Upon doping, the electronic band evolution of conducting polymers is generally accompanied by changes in their optical properties, so that they can be applied as optical switches in electroluminescent devices light-emitting devices and in transparent or anti-reflective films in the automobile and building industries Other applications include their use as surface coatings for visual displays such as CRT screens to avoid electrostatic accumulation of dust and scratching and as photothermographic materials

Conducting polymers such as $\mathrm{PFu}$ are applied to prevent corrosion due to their capacity to disperse electric charge.

\section{Summary}

Although the best means of generating a conducting polymer material is the electrochemical method, some chemical routes have also been employed. Both methods have been developed by varying the electrochemical or chemical experimental conditions, such as the monomer and electrolyte concentrations, temperature, solvent, the dopant anion and the technique for its generation. $\mathrm{PFu}$ nucleation follows a mixture of mechanisms, and a three-dimensional growth of hemispherical nuclei controlled by diffusion has been postulated. As has been described previously, experimental conditions have a great influence on the electrical conductivities of PFu homopolymers in the doped state. A higher degree of hydration and the presence of impurities result in increased conductivity. The highest value measured has been $80 \mathrm{~S} \mathrm{~cm}^{-1}$. Similarly, in PFu composites, co-polymers, and bipolymers, the highest values of $\sigma$ approach $10^{-2} \mathrm{~S} \mathrm{~cm}^{-1}$ in the doped state, this being achieved with larger dopant anions.

The electrochemical behavior of PFu conducting films is not very well defined, with both reversible and irreversible processes being observed. Some authors have found oxidation and reduction processes to be controlled by superficial capacitive charge transfer and by diffusion, respectively.

Progressive $\mathrm{PFu}$ deactivation when the polymer is submitted to continuous cycling is invariably observed. Nevertheless, the conjugated structures in PFu remain undistorted with cycling.

Generally, it has been observed that the redox activity diminishes as the amount of water in the supporting electrolyte is increased.

Spectroscopic techniques such as IR, UV, XPS, ESR, and NMR have been used to elucidate polymer electronic structure and hence the electronic properties that relate to the conductivity of the material.

With the aid of IR techniques, it has been established that the polymer is formed by head-to-tail coupling of the carbon backbone. Moreover, IR spectroscopy has also revealed the existence of open segments in the polymer chains, the optimal experimental conditions for obtaining the most conjugated $\mathrm{PFu}$ films, the degradation of doped films in different media, etc. UV/Vis spectroscopy has shown the relationship between the wavelength of UV absorption and the oxidation potentials of furan rings. The application of XPS confirmed the presence of $\mathrm{C}=\mathrm{O}$ groups and that counterions are always present. ESR measure- 
ments have yielded information on the nature of polymer-chain defects and how these relate to the conduction mechanism. Finally, NMR results have confirmed the structure suggested by IR data.

Different surface morphologies of $\mathrm{PFu}$ films have been reported, depending on the nature of the dopant anion. They have varied from an ordered nodular structure to a granular spongelike one. When polyfuran was synthesized with other polymers as a composite material, its superficial morphology was seen to depend on the cover polymer.

Transmission electron microscopy has been used to probe the existence of a certain crystallinity in polyfuran films, which is not normally seen in other conducting films. This has also been observed by X-ray diffraction analysis. This crystallinity was enhanced in composites with poly(2-halogenoaniline)s.

Polyfuran films have been found to be thermally stable up to $100^{\circ} \mathrm{C}$ in all analyzed cases. This stability could be increased by changing the dopant anion and the synthesis conditions, or by fabricating composites with other polymers.

Magnetic susceptibility measurements have allowed the distinction of paramagnetic and diamagnetic properties for $\mathrm{PFu}$.

Theoretical ab initio calculations on $\mathrm{PFu}$ have been performed in order to assess the effect of $\alpha, \beta$ linkages on its electronic structure and conduction properties, and to study the geometry and band structures of its derivatives or co-polymers with thiophene and pyrrole.

Semi-empirical techniques have also been applied to $\mathrm{PFu}$ to determine the heteroatom effect on the $\pi$-band structure, geometries, ionization potentials, and electron affinities. A semiempirical vibrational assignment has been proposed for the IR spectrum of pristine PFu. An effective conjugation coordinate (ECC) model has been elaborated to assign the vibrational bands.

Density functional theory with a slightly modified B3P86 hybrid functional has been applied to PFu and gas-phase furan dimer.

UV/Vis absorption spectra of syn and anti PFu oligomers have also been simulated by semi-empirical methods. Semiempirical and ab initio methods applied to PFu oligomers and its derivatives have been compared. The consequences of doping processes have also been studied. Good agreement was found between the experimental and theoretical Raman spectra of PFu.

The presence of hydrogen bonds between two adjacent furan rings has been postulated, which enhances the electronic charge transfer. These results provide a model for $\mathrm{PFu}$ chains. Although polyfuran conducting polymers have been less extensively studied than other such polymers due to the difficulties in their synthesis, as we have pointed out previously, their possible technological applications are enormous and are increasing on a daily basis, as this review reflects.

The current trend in PFu conducting polymers is the fabrication of mixtures of PFu with other types of polymers in order to enhance its physical and chemical properties. The evolution of the conducting polymers field over the last 40 years represents excellent technological progress, which is only now beginning to be commercially realized, and can be expected to continue developing in a wide variety of applications.

\section{References}

J. Upadhyay, P. Gaston, A.A. Levy, A. Wassermann, J. Chem. Soc. (1965) 3252 .

C.F. Blakeley, R.S. Gillespie, L. Roubinek, A. Wassermann, R.F.M. White, J. Chem. Soc. (1961) 1939.

J. Upadhyay, J.B.G. Wallace, A. Wassermann, Polymer 7 (9) (1966) 465. P.V. French, L. Roubinek, A. Wassermann, J. Chem. Soc. (1961) 1953. A.G. Davies, A. Wassermann, J. Polymer Sci. A 4 (7) (1966) 1887.

P.H. Plesch (Ed.), The Chemistry of Cationic Polymerisation, Oxford Pergamon Press, 1963.

J.D. Prugh, A.C. Huitric, W.C. McCarthy, J. Org. Chem. 29 (1964) 1991. A. Gandini, Adv. Polym. Sci. 25 (1977) 47.

G. Tourillon, F. Garnier, J. Electroanal. Chem. 135 (1982) 173.

S. Pons, A. Scott Hinman, Electrochim. Acta 29 (9) (1984) 1251.

T. Oshawa, K. Kaneto, K. Yoshino, Jpn. J. Apply Phys. 23 (9) (1984) L663.

F. Tedjar, Eur. Polym. J 21 (1985) 317.

H.S. Nalwa, Phys. Rev. B 39 (9) (1989) 5964.

G. Zotti, G. Schiavon, N. Comisso, A. Berlin, G. Pagani, Synth. Met. 36 (1990) 337.

B. Nessakh, Z. Kotkowska-Machnik, F.J. Tedjar, Electroanal. Chem. 296 (1990) 263.

G. Troch-Nagels, R. Winand, A. Weymeersch, L. Renard, J. Appl. Electrochem. 22 (1992) 756.

S. Glenis, M. Benz, E. LeGoff, J.L. Schindler, C.R. Kannewurf, M.G. Kanatzidis, J. Am. Chem. Soc. 115 (1993) 12519.

M.J. González-Tejera, I. Carrillo, I. Hernández-Fuentes, Anal. Quim. 89 (4) (1993) 521 .

M.J. González-Tejera, I. Carrillo, I. Hernández-Fuentes, Synth. Met. 92 (1998) 187

M.J. González-Tejera, I. Carrillo, J. Appl. Electrochem. 32 (2002) 447.

B. Demirboğa, A.M. Önal, Synth. Met. 99 (1999) 237.

X. Wan, F. Yan, S. Jin, X. Liu, G. Xue, Chem. Mat. 11 (1999) 2400.

X.-B. Wan, L. Li, J.-B. He, D.-S. Zhou, G. Xue, T.-W. Wang, J. Appl. Polym. Sci. 86 (2002) 3160.

M. Talu, M. Kabasakolğlu, F. Yildirin, B. Sari, Appl. Surf. Sci. 181 (2001) 51.

I. Carrillo, E. Sánchez de la Blanca, M.J. González-Tejera, Polymer 42 (2001) 9447 .

M. Kabasakaloğlu, M. Talu, F. Yildirim, B. Sari, Appl. Surf. Sci. 218 (2003) 84.

C. Liu, J. Zhang, G. Shi, Y. Zhao, J. Phys. Chem. 108 (2004) 2195.

T. Ogawa, T. Igarashi, T. Kawanishi, T. Kitamura, K. Hoshino, J. Photopolym. Sci. Technol. 17 (2004) 143.

M.A. del Valle, L. Ugalde, F.R. Díaz, M.E. Bodini, J.C. Bernède, J. Appl. Polym. Sci. 92 (2004) 1346.

M.A. del Valle, L. Ugalde, F. Pino, F.R. Diaz, J.C. Bernède, J. Braz. Chem. Soc. 15 (2) (2005) 272.

S. Tirkeş, A.M. Önal, J. Appl. Polm. Sci. 103 (2006) 871.

M. Zou, J. Heinze, J. Phys. Chem. B 103 (40) (1999) 9451.

K. Imanishi, M. Satho, Y. Yasuda, R. Tsushima, S. Auki, J. Electroanal. Chem. 242 (1-2) (1988) 203.

B. Sari, A. Gök, M. Talı, E. Kim. 14 (4) (2001) 1497.

A. Gök, B. Sari, M. Talu, J. Appl. Polym. Sci. 89 (2003) 2823.

A. Gök, B. Sari, M. Talu, J. Appl. Polym. Sci. 88 (2003) 2924.

A. Gök, B. Sari, M. Talu, J. Polym. Sci. B: Polym. Phys. 42 (2004) 3359.

A. Gök, B. Sari, M. Talu, J. Appl. Polymer. Sci. 98 (2005) 2048.

N. Ballav, M. Biswas, Polym. Int. 53 (2004) 1467.

N. Ballav, M. Biswas, Polym. Int. 54 (4) (2005) 725.

A. Gök, H. Kaplan Can, B. Sari, M. Talu, Mater. Lett. 59 (2005) 80. 
X. Wan, W. Zhang, S. Jin, G. Xue, Q.-D. You, B. Che, J. Electroanal. Chem. 470 (1999) 23.

R.M. McConnell, W.E. Godwin, S.E. Baker, K. Powell, M. Baskett, A. Morara, et al., J. Undergraduate Chem. Res. 3 (2002) 121.

L. Li, W. Chen, N. Xu, Z. Xiao, G. Xue, J. Mater. Sci. 39 (2004) 2395.

R.M. McConnell, W.E. Godwin, S.E. Baker, K. Powell, M. Baskett, A. Morara, Int. J. Polym. Mater. 53 (2004) 697.

A. Diaz, F. Bargon, in: T.A. Skotheim (Ed.), Handbook of Conducting Polymers, vol. 1, Marcel Dekker, Inc., New York, 1986, pp. 81-115.

M.J. González-Tejera, I. Carrillo Ramiro, I. Hernández-Fuentes Electrochim. Acta 45 (2000) 1973.

L. Li, X. Wan, G. Xue, Chin. J. Polym. Sci. 20 (2002) 419.

S. Sadki, P. Schottland, N. Brolic, G. Sabouraud, Chem. Soc. Rev. 29 (2000) 283 .

G. Tourillon, in: T.A. Skotheim (Ed.), Handbook of Conducting Polymers, vol. 1, Marcel Dekker, Inc., New York, 1986, pp. 293-349.

V.V. Korshak, A.S. Sultanov, A.A. Abduvadiev, Uzb. Khim. Zh. 4 (1959) 39.

V.V. Korshak, A.S. Sultanov, A.A. Abduvadiev, USSR CA 54 (1960) 12642 .

A.V. Topchiev, Y.Y. Goldfarb, B.A. Krentsel, Vysokomol. Soedin 3 (1961) 870 .

A.V. Topchiev, Y.Y. Goĺdfarb, B.A. Krentsel, J. Polym. Sci. USSR 3 (1962) 696 .

H.K. Livingston, US. A1. Energy Comm. (1971), COO-1580-13,9 pp. Avail. Dep. NTS.

H.K. Livingston, R. Senkus, J.T.T. Hsieh, J. Kresta, Makromol. Chem. 161 (1972) 101.

A. Granzow, J. Wendenburg, A. Henglein, Z. Naturforsch. B. 19b (1964) 1015 .

H.K. Livingston, R. Senkus, J.T.T. Hsieh, Polym. Prepr. Am. Chem. Soc. Div. Polym. Chem. 11 (1) (1970) 304.

J. Kresta, H.K. Livingston, J. Polym. Sci. Polym. Lett. 8 (1970) 795.

H.K. Livingston, J. Kresta, Polym. Prepr. Am. Chem. Soc. Div. Polym. Chem. 12 (1) (1971) 628 .

K. Shindo, S. Ishikawa, Nippon Kagaku Kaishi 2 (1977) 245.

M. Armour, A.G. Davies, J. Upadhyay, A. Wassermann, J. Polym. Sci. A-1 5 (1967) 1527.

B.S. Lamb, P. Kovacic, J. Polym. Sci. Polym. Chem. 18 (1980) 2423.

K. Yoshino, S. Hayashi, R. Sugimoto, Jpn. J. Apply Phys. 23 (12) (1984) L899.

F. Benvenuti, A.M. Raspolli Galletti, C. Carlini, G. Sbrana, Polymer 38 (19) (1997) 4973.

C.G. Wu, H.O. Marcy, D.C. DeGroot, J.L. Schindler, C.R. Kannewurf, W.Y. Leung, et al., Synth. Met. 41-43 (1991) 797.

R. McConnell, W. Godwin, B. Phillips, J. Ark. Acad. Sci. 51 (1997) 205.

G.C. Teare, N.M. Ratcliffle, R.J. Ewen, J.R. Smith, S.A. Campbell, Smart Mater. Struct. 12 (2003) 129

X.-G. Li, Y. Kang, M.R. Huang, J. Comb. Chem. 8 (5) (2006) 670. P.K. Abraham, K. Sathianandan, Thin Solid Films 164 (1988) 353. D.S. Kumar, J. Mater. Sci. 35 (2000) 4427.

M.H. Qiao, F.Q. Yan, W.S. Sim, J.F. Deng, G.Q. Xu, Surf. Sci. 460 (2000) 67.

F.Q. Yan, M.H. Qiao, X.M. Wei, Q.P. Liu, J.F. Deng, G.Q. Xu, J. Chem. Phys. 111 (17) (1999) 8068.

M. Fleischman, H.R. Thirsk, in: P. Delahay, C.W. Tobias (Eds.), Advances Electrochemical Engineering, Interscience, New York, 1963, pp. $123-210$.

M.J. González-Tejera, I. Carrillo, I. Hernández-Fuentes, Synth. Met. 73 (1995) 135.

V. Hernández, F.J. Ramirez, G. Zotti, J.T. López Navarrete, Chem. Phys. Lett. 191 (5) (1992) 419.

V. Hernández, M. Veronelli, L. Favaretto, J.T. López Navarrete, D. Jones, G. Zerbi, Acta Polym. 47 (1) (1996) 62.

J.T.López Navarrete, V. Hernández, G. Zotti, M. Veronelli, G. Zerbi, Acta Polym. 45 (1994) 124.
V. Hernández, J.T. López Navarrete, G. Zotti, M. Veronelli, G. Zerbi, Synth. Met. 69 (1995) 391.

I. Carrillo, E. Sánchez de la Blanca, M.J. González-Tejera, I. HernándezFuentes, Chem. Phys. Lett. 229 (1994) 633.

E. Sánchez de la Blanca, I. Carrillo, M.J. González-Tejera, I. HernándezFuentes, J. Polym. Sci. Polym. Chem. 38 (2000) 291.

I. Carrillo, F. Fernández-Martín, C. Barba, E. Sánchez de la Blanca, M.J. González-Tejera, I. Hernández-Fuentes, Polym. Bull. 43 (1999) 269.

D.S. Kumar, J. Appl. Polym. Sci. 75 (2000) 1176.

A. Galal, E.T. Lewis, O. Yavuz Ataman, H. Zimmer, H.B. Mark, J. Polym. Sci. A: Polym. Chem. (1989) 1891.

I. Carrillo, C. Barba, M.J. González-Tejera, J.L. Baldonedo, I. HernándezFuentes, Les Editions de Physique 2B (1994) 1213.

I. Carrillo, M.J. González-Tejera, I. Hernández-Fuentes, C. Barba, Solid State Commun. 95 (2) (1995) 107.

I. Carrillo, C. Barba, M.J. González-Tejera, I. Hernández-Fuentes, Macromolecules 29 (17) (1996) 5585.

I. Carrillo Ramiro, M.J. González-Tejera, J. Polym. Int. 49 (2000) 1565.

S. Wang, T. Kawai, K. Yoshino, K. Tanaka, T. Yamabe, Jap. J. Appl. Phys. 29 (12) (1990) L2264.

J.W. Mintmire, C.T. White, M.L. Elert, Synth. Met. 25 (1988) 109.

V.T. Hernández, J.T. López Navarrete, J.L. Marcos, Synth. Met. 41-43 (1991) 789 .

G. Distefano, D. Jones, M. Guerra, L. Favaretto, A. Modelli, G. Mengoli, J. Phys. Chem. 95 (1991) 9746.

V. Hernández, F.J. Ramirez, G. Zotti, J.T. López Navarrete, Synth. Met. 55-57 (1993) 4467.

V. Hernández, F.J. Ramirez, G. Zotti, J.T.López Navarrete, J. Chem. Phys. 98 (2) (1993) 769.

S.Y. Hong, Bull. Korean Chem. Soc. 16 (9) (1995) 845.

A.K. Bakhshi, Y. Yamaguchi, H. Ago, T. Yamabe, Mol. Eng. 6 (1996) 239.

I. Ivanov, B.F. Gherman, D. Yaron, Synth. Met. 116 (2001) 111.

R.L. Doretto, B. Laks, Synth. Met. 19 (2001) 543.

R.L. Doretto, B. Laks, J. Chem. Phys. 117 (11) (2002) 5437.

G.R. Hutchison, M.A. Ratner, T.J. Marks, J. Phys. Chem. 106 (2002) 10596.

S.Y. Hong, Bull. Korean Chem. Soc. 24 (7) (2003) 961.

A.K. Bakhshi, N.K. Ray, J. Chem. Phys. 88 (1) (1988) 386.

A.K. Bakhshi, J. Ladik, M. Seel, Phys. Rev. B 35 (2) (1987) 704.

A.K. Bakhshi, J. Chem. Phys. 96 (3) (1992) 2339.

H.O. Villar, P. Otto, M. Dupuis, Synth. Met. 59 (1993) 97.

A. Balbás, M.J. González-Tejera, J. Tortajada, J. Mol. Struct. (Theochem.) 572 (2001) 141.

P. Otto, M. Piris, A. Martinez, J. Ladik, Synth. Met. 141 (2004) 277.

P. Leiva, A. Martinez, P. Otto, Synth. Met. 150 (2006) 648.

S.S. Zade, M. Bendikov, Org. Lett. 8 (23) (2006) 5243.

R.V. Bantaculo, A.C. Alguno, R.M. Vequizo, M.B. Muñoz, M.F.H. Miyata, E.W. Ignacio, et al., The Mindanao Forum XV (2) (2001).

U. Salzner, J.B. Lagowski, P.G. Pickup, R.A. Poirier, Synth. Met. 96 (1998) 177.

J. Ma, S. Li, Y. Jiang, Macromolecules 35 (2002) 1109.

G.R. Hutchison, Y.-J. Zhao, B. Delley, A.J. Freeman, M.A. Ratner, T. Marks, J. Phys. Rev. B. 68 (2003) 035204.

G.R. Hutchison, M.A. Ratner, J.M. Tobin, J. Am. Chem. Soc. 127 (7) (2005) 2339

M. Montejo, A. Navarro, G.J. Kearley, J. Vázquez, J.J. López-González, J. Am. Chem. Soc. 126 (46) (2005) 15087.

GG. Wallace, PCT Int. Appl. (1989); 8907265, Chem. Abstr. 110 (1989) 68673 s.

K. Ito, G. Tanabe, M. Sato, K. Kaeriyama, Jpn. Kokai Tokkyo Koho (1989); 01289012, Chem. Abstr. 112 (1990) 170332h.

H. Shimada, K. Sakamoto, K. Inoe, Jpn. Kokai Tokkyo Koho (1990); 02117121, Chem. Abstr. 113 (1990) 124913w.

Y. Arracima, A. Inoue, Jpn. Kokai Tokkyo Koho (1990); 02137310, Chem. Abstr. 113 (1990) 143669n. 
Y. Kudoh, S. Tsuchiya, T. Kojima, M. Fukuyama, S. Yoshimura, K. Kuranuki, Eur. Pat. Appl. (1990); 358239, 113 Chem. Abstr. (1990) 163994t.

K. Kuranuki, J. Ozaki, Y. Aoshima, Y. Obata, M. Taniguchi Jpn. Kokai Tokkyo Koho (1990); 02298010, Chem. Abstr. 114 (1991) 258196u

K. Kuranuki, J. Ozaki, Y. Aoshima, Y. Obata, Jpn Kokai Tokkyo Koho 03096210 (1991), Chem. Abstr. 115 (1991) 172887d.

S. Imoto, Y. Kado, T. Mori, Jpn. Kokai Tokkyo Koho (1991); 03070117:03071617: 03080522:03072615:03071618, Chem. Abstr. 115 (1991) 172874x:172873w:148443k: 148441h:148437m.

H. Shimada, K. Sakamoto, Y. Harashima, Jpn. Kokai Tokkyo Koho (1991); 03064013:03064014, Chem. Abstr. 115 (1991) 221240y: 221239 e.

M. Kobayashi, K. Naito, S. Kawakami, Jpn Kokai Tokkyo Koho (1991); 03114213, Chem. Abstr. 115 (1991) 221288v.

Y. Obata, J. Ozaki, Y. Aoshima, K. Kuranuki, Jpn. Kokai Tokkyo Koho (1991); 03178117, Chem. Abstr. 115 (1991) 268722x.

J. Ozaki, Y. Aoshima, K. Kuranuki, Y. Obata, Jpn. Kokai Tokkyo Koho (1991); 03179717, Chem. Abstr. 115 (1991) 293080 u.

S. Ookubo, K. Hitosugi, M. Kazuhara, Jpn. Kokai Tokkyo Koho (1993); 05166681, Chem. Abstr. 120 (1994) 93283d.

N. Honda, Jpn. Kokai Tokkyo Koho (1994); 06168851, Chem. Abstr. 121 (1994) 168570b.

T. Fukami, Jpn. Kokai Tokkyo Koho (1994); 06204099, Chem. Abstr. 121 (1994) $243683 \mathrm{w}$.

T. Matsui, Jpn. Kokai Tokkyo Koho (1994); 06204093 , Chem. Abstr. 121 (1994) 243679z.

Y. Shimamoto, Jpn. Kokai Tokkyo Koho (1995); 07240343, Chem. Abstr. 124 (1996) 19932f

T. Kojima, K. Yoshida, Y. Kudo, M. Murakami, Jpn. Kokai Tokkyo Koho (1996); 08083735, Chem. Abstr. 125 (1996) 46992c.

S. Takayama, S. Arai, Jpn. Kokai Tokkyo Koho (1996); 08273982, Chem. Abstr. 126 (1996) 41451m.

Y. Aoki, K. Araki, T. Hukaumi, K. Takahashi, D. Takada, Eur. Pat. Appl. (1999); 952593, Chem. Abstr. 131 (1999) 294448n.

R. Monden, A. Sakai, Y. Furuta, H. Ohata, Jpn. Kokai Tokkyo Koho (2001); 2001006982 , Chem. Abstr. 134 (2001) 79811.

K. Naoi, A. Kadota, Y. Yoshihara, M. Kobayashi, Jpn. Kokai Tokkyo Koho (2005); 2005191127 , Chem. Abstr. 143 (2005) 89218.

H. Hasegawa, Jpn. Kokai Tokkyo Koho (2005); 2005136336, Chem. Abstr. 142 (2005) 474422.

F. Tatsuzono, Y. Hirata, H. Kamikawa, Jpn. Kokai Tokkyo Koho (2002); 2002128877, Chem. Abstr. 136 (2002) 378560.

H. Ohata, K. Shirane, R. Monden, A. Sakai, US 2003; 6660188:6663796, Chem. Abstr. 140 (2004) 22063.

H. Naarmann, H. Hartmann, W. Denzinger, Ger. Offen. (1991); 3938094 , Chem. Abstr. 115 (1991) 195966 t.

H. Koshina, H. Okuno, T. Morita, Jpn. Kokai Tokkyo Koho (1992); 04002065, Chem. Abstr. 116 (1992) 218168w.

I. Nakane, Y. Fujita, S. Furukawas, Jpn. Kokai Tokkyo Koho (1992);04028172, Chem. Abstr. 116 (1992) 259053y.

T. Oosawa, K. Yoshino, K. Kanefuji, Jpn. Kokai Tokkyo Koho (1993) 05209043, Chem. Abstr. 121 (1994) 24680q.
M. Fujimoto, N. Toma, K. Nishio, Jpn. Kokai Tokkyo Koho (2000);2000030692, Chem. Abstr. 132 (2000) 110595z.

R. Bittihn, F. Woeffler, Ger. Offen. (1986); 3443455, Chem. Abstr. 105 (1986) 46385u.

J. Murakami, S. Tsurumaki, T. Ueda, Jpn. Kokai Tokkyo Koho (1996); 08339826, Chem. Abstr. 126 (1997) 174290e.

H. Hasegawa, Jpn. Kokai Tokkyo Koho (2005); 2005105000, Chem. Abstr. 142 (2005) 356470.

B. Srinivas, PCT Int. Appl. (2003);2003100883, Chem. Abstr. 139 (2003) 398064.

B. Srinivas, PCT Int. Appl. (2003);2003100884, Chem. Abstr. 2003; 139. M.C. Kuo, W.R. Hoover, M.W. Akkala, W. Mehlhorn, US Pat. Appl. (2005); 2005062350, Chem. Abstr. 142 (2005) 398065.

B. Srinivas, A. Dotson, O. US Pat. Appl. (2004);2004109816, Chem. Abstr. 141 (2004) 26123.

B. Srinivas, US Pat. Appl. (2004); 2004144961:2004166401, Chem. Abstr. 141 (2004) 143235:193065.

W.K. Um, YG. Woo, Repub. Korean Kongkae Taeho Kongbo (2005) 2001063674 , Chem. Abstr. 142 (2005) 157963.

M.C. Kuo, W.R. Hoover, M.W. Akkala, W.L. Mehlhom, US Pat. Appl. Publ. (2005); 2005062350, Chem. Abstr. 142 (2005) 282618

R. Hasler; V. Sanahuja, PCT Int. Appl. (1993); 9320569, Chem. Abstr. 120 (1994) $81556 \mathrm{~g}$.

T. Skotheim, US Pat. Appl. (1984); 4442185, Chem. Abstr. 101 (1984) $10053 n$.

S. Chen, M. Hua, Eur. Pat. Appl. (1995);673042, Chem. Abstr. 123 (1995) $327682 z$.

M. Angelopoulos, J.J. Bucchignano, K.E. Petrillo, Jpn. Kokai Tokkyo Koho (1999); 11203937, Chem. Abstr. 131 (1999) 137786d.

N. Tachibana, C. Kotani, S. Okamura, S. Morita, Jpn. Kokai Tokkyo Koho (1996) 08201978, Chem. Abstr. 125 (1996) 288712d.

K. Bruens, M. Franz, J. Jansen, G.A. Frank, P.M. Tijsen, P. Hubert et al., Jpn. Kokai Tokkyo Koho (2001); 2001081413, Chem. Abst.r 134 (2001) 259938.

J.Y. Kim, E.R. Kim, Jpn. Kokai Tokkyo Koho (2003); 2003082105, Chem. Abstr. 138 (2003) 246786.

A. Piller, Ger. Offen. (1991); 4006134, Chem. Abstr. 116 (1992) 22233u. P. Schindler-Bauer, M. Liebau, H. Klauk, E. Unger, Ger. Offen. (2004); 10226945, Chem. Abstr. 140 (2004) 69092.

F. Jonas, A. Elschner, R. Wehrmann, D. Quintens, Ger. Offen. (1998); 19627071, Chem. Abstr. 128 (1998) 134182f.

M. Angelopoulos, D.D. Dimitrakopoulos, B.K. Furman, T.O. Graham, S.A. Lien, PCT In. Appl. (1998);9821755, Chem. Abstr. 129 (1998) 35190w.

A. Tokuda, T. Takasu, S. Seo, R. Nomura, PCT Int. Appl. (2004);2004062322, Chem. Abstr. 141 (2004) 147851.

A. Afzali-Ardakani, M. Angelopoulos, J.A. Dickerson, T.B. Pillsbury, K.J. Puttlitz, J.M. Shaw et al. Eur. Pat. Appl . (1993);567835, Chem. Abstr. 121 (1994) $71597 \mathrm{c}$.

T. Hanyu, Jpn. Kokai Tokkyo Koho (2002); 2002196452, Chem. Abstr. 137 (2002) 101464.

D.B. Dowling, PCT Int. Appl. (2002); 2002101117, Chem. Abstr. 138 (2003) 27537. 